\title{
Emerging and legacy per- and polyfluoroalkyl substances in water, sediment, and air of the Bohai Sea and its surrounding rivers ${ }^{\text {tr }}$
}

\author{
Zhen Zhao ${ }^{\mathrm{a}, 1}$, Xianghui Cheng ${ }^{\mathrm{b}, 1}$, Xia Hua ${ }^{\mathrm{c}}$, Bin Jiang ${ }^{\mathrm{e}}$, Chongguo Tian ${ }^{\mathrm{d}}$, Jianhui Tang ${ }^{\mathrm{d}, *}$,

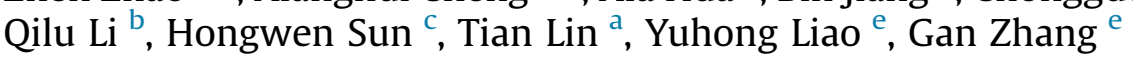 \\ a College of Marine Ecology and Environment, Shanghai Ocean University, Shanghai, 201306, China \\ ${ }^{\mathrm{b}}$ Key Laboratory for Yellow River and Huai River Water Environment and Pollution Control, Ministry of Education, Henan Key Laboratory for Environmental \\ Pollution Control, School of Environment, Henan Normal University, Xinxiang, 453007, China \\ ${ }^{c}$ MOE Key Laboratory of Pollution Processes and Environmental Criteria, College of Environmental Science and Engineering, Nankai University, Tianjin, \\ 300071, China \\ ${ }^{\mathrm{d}}$ Key Laboratory of Coastal Environmental Processes and Ecological Remediation, Yantai Institute of Coastal Zone Research, Chinese Academy of Sciences, \\ Yantai, 264003, China \\ e State Key Laboratory of Organic Geochemistry, Guangzhou Institute of Geochemistry, Chinese Academy of Sciences, Guangzhou, 510640, China
}

\section{A R T I C L E I N F O}

\section{Article history:}

Received 13 December 2019

Received in revised form 12 March 2020

Accepted 14 March 2020

Available online 16 March 2020

\section{Keywords:}

Perfluoroalkyl and polyfluoroalkyl

substances

Bohai Sea

Distribution coefficient

Riverine discharge fluxes

Nontarget suspect compounds

\begin{abstract}
A B S T R A C T
Per- and polyfluoroalkyl substances (PFASs) contamination in the Bohai Sea and its surrounding rivers has attracted considerable attention in recent years. However, few studies have been conducted regarding the distribution of PFASs in multiple environmental media and their distributions between the suspended particles and dissolved phases. In this study, surface water, surface sediment, and air samples were collected at the Bohai Sea to investigate the concentration and distribution of 39 targeted PFASs. Moreover, river water samples from 35 river estuaries were collected to estimate PFAS discharge fluxes to the Bohai Sea. The results showed that total ionic compound ( $\Sigma i$-PFASs) concentrations ranged from 19.3 to $967 \mathrm{ng} / \mathrm{L}$ (mean $125 \pm 152 \mathrm{ng} / \mathrm{L}$ ) in the water and $0.70-4.13 \mathrm{ng} / \mathrm{g} \mathrm{dw}(1.78 \pm 0.76 \mathrm{ng} / \mathrm{g}$ ) in surface sediment of the Bohai Sea, respectively. In the estuaries, $\Sigma i$-PFAS concentrations were ranged from 10.5 to $13500 \mathrm{ng} / \mathrm{L}(882 \pm 2410 \mathrm{ng} / \mathrm{L})$. In the air, $\Sigma$ PFAS $(\Sigma \mathrm{i}$-PFASs $+\Sigma$ n-PFASs $)$ concentrations ranged from 199 to $678 \mathrm{pg} / \mathrm{m}^{3}\left(462 \pm 166 \mathrm{pg} / \mathrm{m}^{3}\right)$. Perfluorooctanoic acid (PFOA) was the predominant compound in the seawater, sediment, and river water; in the air, 8:2 fluorotelomer alcohol was predominant. Xiaoqing River discharged the largest $\Sigma \mathrm{i}$-PFAS flux to the Bohai Sea, which was estimated as $12,100 \mathrm{~kg} / \mathrm{y}$. Some alternatives, i.e., 6:2 fluorotelomer sulfonate acid (6:2 FTSA), hexafluoropropylene oxide dimer acid (HFPO-DA), and chlorinated 6:2 polyfluorinated ether sulfonic acid (Cl-6:2 PFESA), showed higher levels than or comparable concentrations to those of the C8 legacy PFASs in some sampling sites. The particlederived distribution coefficient in seawater was higher than that in the river water. Using high resolution mass spectrometry, 29 nontarget emerging PFASs were found in 3 river water and 3 seawater samples. Further studies should be conducted to clarify the sources and ecotoxicological effects of these emerging PFASs in the Bohai Sea area.
\end{abstract}

() 2020 Elsevier Ltd. All rights reserved.

\section{Introduction}

Per- and polyfluoroalkyl substances (PFASs) are a class of anthropogenic surfactants with the perfluoroalkyl moiety $C_{n} F_{2 n-1}^{-}$

\footnotetext{
* This paper has been recommended for acceptance by Maria Cristina Fossi.

* Corresponding author.

E-mail address: jhtang@yic.ac.cn (J. Tang).

${ }^{1}$ These authors contributed equally to this work.
}

(Buck et al., 2011). Due to high surface activity, thermal stability, and hydrophobic and lipophobic properties, PFASs have been widely used in industrial and household products, including surfactants, fire-fighting foams, metal plating, and textiles, for more than six decades (Wang et al., 2009; Zhou et al., 2013). PFASs can be divided into two major classes, i.e., ionic PFASs (i-PFASs) and neutral PFASs ( $n$-PFASs). $i$-PFASs have been found in water and sediment from riverine, lacustrine, coastal, oceanic, and polar environments (MacInnis et al., 2019; Pan et al., 2018; Zhou et al., 2018; Zhou et al., 2013) and n-PFASs are mainly distributed in the air, 
particularly in the Northern Hemisphere (Genualdi et al., 2010; Wang et al., 2015b). Furthermore, $C 8$ homologues $\left(\mathrm{C}_{8} \mathrm{~F}_{17}\right.$ and $\left.\mathrm{C}_{8} \mathrm{~F}_{15}\right) \mathrm{C}_{8} \mathrm{~F}_{17}^{-} \mathrm{C}_{8} \mathrm{~F}_{15}^{-}$such as perfluorooctane sulfonate acid (PFOS) and perfluorooctanoic acid (PFOA), have been reported to be toxic and potentially carcinogenic, and their manufacture has been decreased or phased-out since 2000 (Florentin et al., 2011; UNEP, 2009, 2017; USEPA, 2000, 2006; Wang et al., 2015a).

After the phaseout of C8 homologues in developed countries, production was shifted to developing countries because of the huge domestic and international demands and relatively poor regulations regarding production of these chemicals (Liu et al., 2016a; Liu et al., 2016b). The manufacture of perfluorooctanesulfonyl fluoride (POSF) in China increased after 2002 (Meng et al., 2015), which could explain the elevated levels of POSF in the Pearl River Delta in 2004 (Lim et al., 2011). Moreover, the short-chained perfluoroalkyl sulfonic acids ( $C<8$ PFSAs) (e.g., perfluorobutanesulfonic acid (PFBS)) and perfluoroalkyl carboxylic acids (PFCAs) (e.g., perfluorobutanoic acid (PFBA)) are applied in commercial products as substitutes for PFOA and PFOS, resulting in their occurrences in riverine and coastal waters (Pan et al., 2018; Zhou et al., 2018). Recently, more alternatives have aroused great concern, for instances, Heydebreck et al. (2015) reported high hexafluoropropylene oxide dimer acid (HFPO-DA) concentrations in a river impacted by emissions from a fluorochemical industrial park (Heydebreck et al., 2015) and Song et al. (2018) found more HFPO oligomers (hexafluoropropylene oxide trimer acid (HFPO-TrA) and hexafluoropropylene tetramer acid (HFPO-TeA)) in the same area (Song et al., 2018). High ammonium 4,8-dioxa-3H-perfluorononanoate (ADONA) concentrations (up to $6200 \mathrm{ng} / \mathrm{L}$ ) were found in the Alz River, Germany, which receives effluent discharge from a fluorochemical plant (LfU, 2016). HFPO oligomers and ADONA are alternatives for PFOA that can be frequently detected in an area influenced by fluoropolymer plants (Wang et al., 2013c). In addition to these substitutes, nontarget screening studies have discovered more classes of PFCA-based compounds, e.g., monohydrogen-substituted PFCAs (H-PFCAs) and poly hydrogensubstituted PFCAs (xH-PFCAs) (Song et al., 2018; Wang et al., 2018b), and PFASs with ether linkages, e.g., monoether-PFCAs and monoether-PFSAs (Munoz et al., 2019). Several PFSA-based compounds have been employed as PFOS alternatives. Houtz et al. (2016) and Kärrman et al. (2011) reported the occurrence of 6:2 fluorotelomer sulfonate acid (6:2 FTSA) in an area affected by historical use of aqueous film forming foam (AFFF), showing the application and accumulation of FTSAs as PFOS alternatives in fluorotelomer-based AFFF (Houtz et al., 2016; Karrman et al., 2011). Nontarget screening analysis provided a comprehensive list of PFSA-based compounds discovered in AFFF-impacted groundwater (Barzen-Hanson et al., 2017). In the Chinese chromium-plating industry, perfluoroether sulfonic acids (PFESAs) have been used as mist suppressants (Wang et al., 2013b), and chlorinated 6:2 polyfluorinated ether sulfonic acid (Cl-6:2 PFESA) has been ubiquitously detected in Chinese rivers (Pan et al., 2018). Additionally, the use of cyclic perfluoroalkyl acids in hydraulic fluids as anticorrosive agents has led to the occurrence of perfluoroethylcyclohexane sulfonate acid (PFECHS) in water and sediment in an airportimpacted ecosystem in China (de Solla et al., 2012; Wang et al., 2016c).

PFASs released from emissions can transport to the sea and oceans via air and rivers (Ahrens, 2011; Prevedouros et al., 2006; Zhou et al., 2018). Because of the large emission volume and high solubility of i-PFASs, river discharge is a widespread concern as the main pathway for pollutant transportation from land to seas and even deep oceans (Pan et al., 2018; Zhao et al., 2017; Zhao et al., 2013b; Zhou et al., 2018). In river water, the suspended particles are an important carrier but have been typically neglected in previous studies. From the river to the coast, a change in salinity might cause a salting-out effect, particularly in estuaries (Hong et al., 2013). Along the coast and in seas, the distribution between sediment and water is different from that in rivers because of the change in the physical and chemical conditions (Higgins and Luthy, 2006; Hong et al., 2013).

The Bohai Sea is a semi-closed sea in northern China consisting of three bays, i.e. Liaodong, Bohai, and Laizhou bays. Extremely high PFAS concentrations have been detected in adjacent inland and coastal waters because of emission from fluorochemical industrial parks and the contaminants are transported to the Bohai Sea not only by various rivers but also via deposition from the air (Fang et al., 2018; Li et al., 2011; Regnery and Püttmann, 2010; Wang et al., 2014a; Wang et al., 2013a; Zhou et al., 2018). Simultaneous field investigation of PFASs in air, water, and sediment in the semiclosed Bohai Sea are still needed to get a more comprehensive understanding about the PFAS behaviors in the environment.

The objectives of this study were to (1) present the distribution and composition of legacy and alternative PFASs in the water, sediment, and air of the Bohai Sea; (2) estimate the discharge fluxes of PFASs via dissolved and particle phases from main rivers in the study area; and (3) identify more emerging PFASs in coastal water which have been reported in other aquatic ecosystems using high resolution mass spectrometry.

\section{Materials and methods}

\subsection{Sample collection}

A total of 52 surface water samples, 30 surface sediment samples, and 6 air samples were collected in the Bohai Sea between August 25 and September 4, 2017, on the research vessel Chuangxin 1 of the Yantai Institute of Coastal Zone Research, Chinese Academy of Sciences (Fig. 1, Tables S1 and S2). Another 35 surface water samples were collected during December 2017 at river mouths of 35 rivers around the Bohai Sea by car (Table S3).

Surface water samples $(0-30 \mathrm{~cm})$ were collected using a stainless-steel basket, and stored in 1-L polypropylene (PP) bottles (Asone, Osaka, Japan) which were precleaned using methanol prior to use (Zhao et al., 2017). Surface sediment samples $(0-5 \mathrm{~cm}, \sim 5 \mathrm{~g}$ ) were collected using a stainless-steel box corer and stored in a prebaked $\left(450{ }^{\circ} \mathrm{C}\right.$ for $12 \mathrm{~h}$ ) aluminum foil box. Air samples (266 $\pm 24 \mathrm{~m}^{3}$ per sample, $24 \mathrm{~h}$ ) were collected using a high-volume air sampler placed in the front of the ship's upper deck. A glass fiber filter (GFF, $12 \mathrm{~cm}$ in diameter, $0.7-\mu \mathrm{m}$ pore size) combined with a self-packed polyurethane (PUF)/XAD-2 glass column (PUF: $\$ 5.0$ and $2.5 \mathrm{~cm}$ in length; $35 \mathrm{~g}$ XAD-2, particle size: $0.3-1.0 \mathrm{~mm}$ ) were employed to trap PFASs (Wang et al., 2014b; Weiner et al., 2013). All the samples were stored at $-20^{\circ} \mathrm{C}$ before extraction.

\subsection{Extraction and instrumental analysis}

A total of $32 i$-PFASs and $7 n$-PFASs were monitored as target compounds. As internal standards (ISs), 22 mass labeled compounds (17 compounds as IS1 for the $i$-PFASs and 5 compounds as IS2 for the n-PFASs) were employed. All the standards, as listed in Table S4, were purchased from Wellington Laboratories Inc. (Ontario, Canada), the purities of which were greater than $98 \%$.

The extraction steps were performed according to previous studies with modifications (Ahrens et al., 2016; Kaboré et al., 2018; Wang et al., 2014b). Briefly, water samples were filtered through $0.7-\mu \mathrm{m}$ glass fiber filters (Whatman, GF/F, Ø47 mm) to separate the particle and dissolved phases. Filters were frozen at $-20{ }^{\circ} \mathrm{C}$ for 


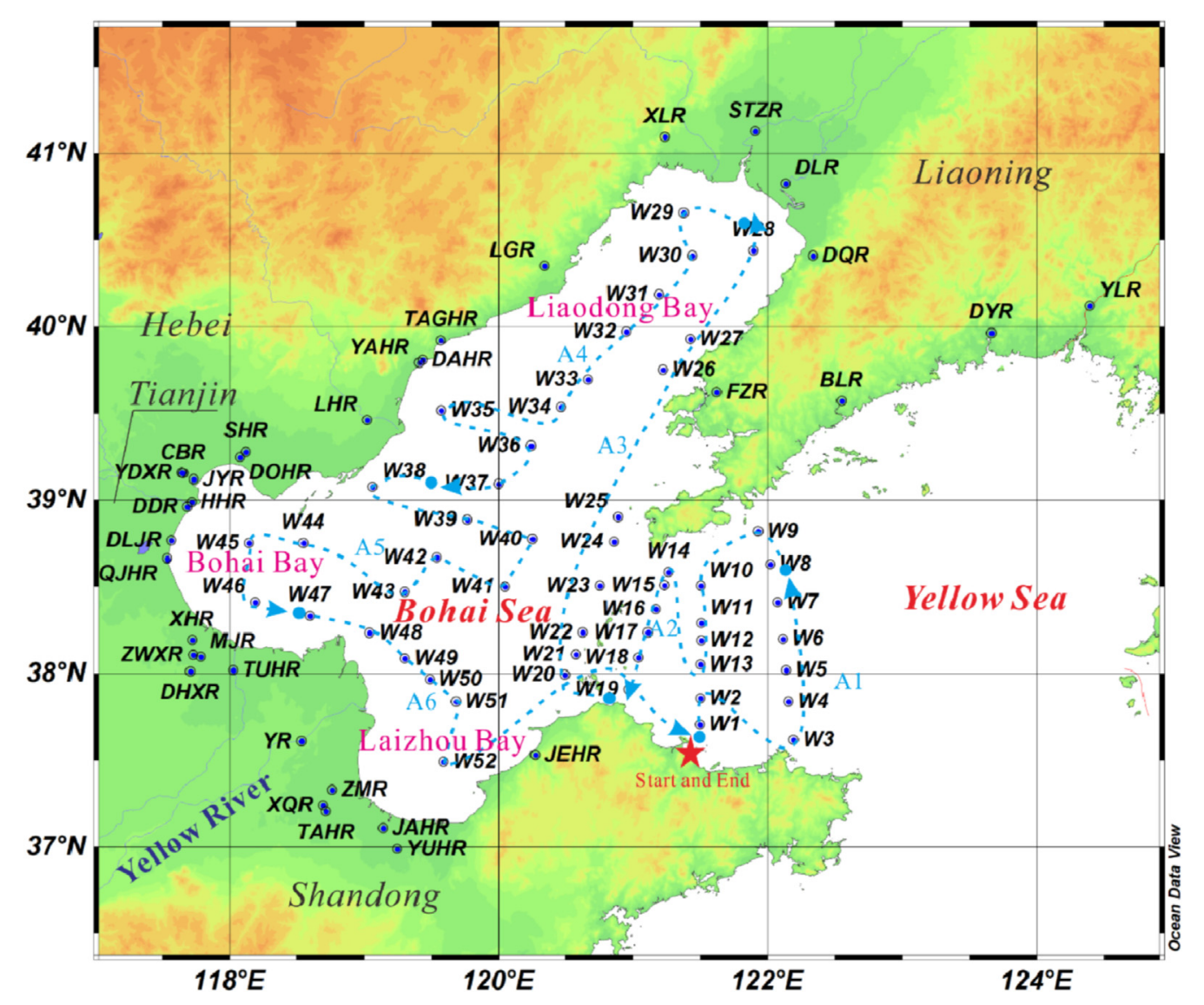

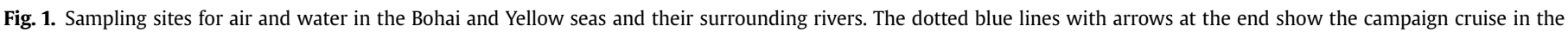

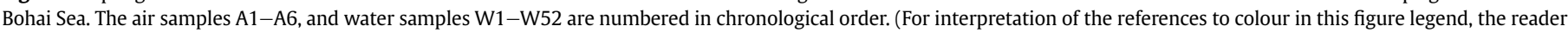
is referred to the Web version of this article.)

further treatment. The dissolved phase was first spiked with $3 \mathrm{ng}$ of IS1 and then solid phase extracted (SPE) using Oasis WAX cartridges (Waters, $150 \mathrm{mg}, 6 \mathrm{~cm}^{3}, 30 \mu \mathrm{m}$ ) at a flow rate of $10 \mathrm{~mL} / \mathrm{min}$. After water loading, the cartridges were washed with $15 \mathrm{~mL}$ of high-performance liquid chromatography (HPLC) grade water (Fisher Scientific, Pittsburgh, USA) to remove the salt and then dried for 30 min with a nitrogen flow (>99.999\%). The target compounds were twice eluted with $4 \mathrm{~mL}$ of methanol with $0.2 \%$ $\mathrm{NH}_{4} \mathrm{OH}$. Water filters, air filters, and sediments were freeze-dried for $72 \mathrm{~h}$ and then twice sonicated for $15 \mathrm{~min}$ with $15 \mathrm{~mL}$ of $0.2 \%$ $\mathrm{NH}_{4} \mathrm{OH}$ in methanol in a PP tube. A clean-up step was performed using ENVI-Carb cartridges (Supelco, $3 \mathrm{~mL}, 250 \mathrm{mg}$ ). Air columns were spiked with $3 \mathrm{ng}$ of IS1 and IS2 and then Soxhlet extracted using both dichloromethane (DCM) and methanol for $24 \mathrm{~h}$. Anhydrous $\mathrm{Na}_{2} \mathrm{SO}_{4}$ was added to remove residual water and then the extracts were concentrated using a rotary evaporator. The volumes of all the extracts were reduced to $200 \mu \mathrm{L}$ under a gentle $\mathrm{N}_{2}$ flow (>99.999\%). Before instrumental analysis, $3 \mathrm{ng} \mathrm{8:2} \mathrm{fluorotelomer}$ unsaturated acid (8:2 FTUCA) as injection standard (InjS) was spiked into each sample for quantification. More details regarding the sample extraction can be found in the Supplemental Information (SI) materials.

Target $i$-PFASs were analyzed using a high-performance liquid chromatography-tandem mass spectrometry system, with an Agilent 1290 series liquid chromatograph interfaced with a 6460 triple quadrupole mass spectrometer (Agilent Technologies, USA). An RSpak JJ-50 2D ion-exchange column ( $2 \mathrm{~mm}$ i.d. $\times 150 \mathrm{~mm}, 5 \mu \mathrm{m}$, CNW, Germany) was used to separate the C2 - C4 PFCAs and a X- terra MS C18 column ( $2.1 \mathrm{~mm}$ i.d. $\times 150 \mathrm{~mm}, 5 \mu \mathrm{m}$, Waters, Ireland) was used to separate the other $i$-PFASs. Target $n$-PFASs were analyzed via gas chromatography-mass spectrometry, with an Agilent 7890B gas chromatograph interfaced with an Agilent 5977B mass spectrometer. A DB-WAX column $(30 \mathrm{~m} \times 0.25 \mathrm{~mm}$ i.d., $0.25 \mu \mathrm{m}$, Agilent J\&W, USA) was used for separation. $n$-PFASs in the air particle phase were not analyzed given that low detection rates were found in previous studies (Wang et al., 2014b).

To identify more emerging PFASs, fourier transform ion cyclotron resonance mass spectrometry (FT-ICR MS; Bruker Daltonik $\mathrm{GmbH}$, Bremen, Germany) was employed in a negative electrospray ionization $\left(\mathrm{ESI}^{-}\right)$mode under a full scan $(150-1500 \mathrm{~m} / \mathrm{z}$ ) with a resolution of $10^{7}$. Referring to previous studies, a list of nontarget PFASs were generated, and PFASs which were not targeted in this study were screening based on accurate molecular mass and isotope peaks (Baduel et al., 2017; Barzen-Hanson et al., 2017; Dauchy et al., 2019; Gebbink et al., 2017; Kabore et al., 2018; Lin et al., 2017; McCord and Strynar, 2019; Mejia-Avendano et al., 2017; Newton et al., 2017; Song et al., 2018; Wang et al., 2018b; Xiao et al., 2017; Xu et al., 2017; Yu et al., 2018a). The Data Analysis 5.0 (Bruker Daltonik) was used to propose molecular formulas by accurate molecular mass. The mass error $(\Delta \mathrm{m})$ less than 5 parts per million (ppm) comparing with theoretical $\mathrm{m} / \mathrm{z}$ with a signal/noise ratio higher than 10 was employed as criterions to refine proposed molecular formulas. The isotope intensity ratios were tested to filter false positive results. All the nontarget compounds from the samples were not detected in three whole-process blanks. Detailed information regarding the instrumental parameters and screening 
processes are shown in the SI materials.

\subsection{Total organic carbon}

The total organic carbon (TOC) contents in the sediment samples were determined using a TOC analyzer (Analytik Jena AG, multi N/C 3100, Germany). Approximately $20 \mathrm{mg}$ of freeze-dried samples were treated with hydrochloric acid $(1.0 \mathrm{~mol} / \mathrm{L})$ to remove carbonate residues before analysis.

\subsection{Air mass back trajectories}

For the air mass back trajectories, the NOAA's HYSPLIT model was employed (http://www.arl.noaa.gov/HYSPLIT_info.php). On the research vessel, the sampling height was about $10 \mathrm{~m}$ above the sea level. Five-day trajectories were calculated in $6 \mathrm{~h}$ steps for each sample. The detailed results are show in Fig. S3.

\subsection{Quality assurance/quality control}

To minimize the risk of unintended contamination, the experimental utensils were all composed of glass and PP. All the utensils and materials that could touch the samples were precleaned before use. The concentration gradient of the target standard curve was 0 , $0.5,1,2,5,10,20,50,100$, and $200 \mu \mathrm{g} / \mathrm{L}$ and the $\mathrm{R}$ values for the individual compounds were all greater than 0.993. Instrumental quantification limits (IQLs) were defined as the lowest concentration of target compounds resulting in a signal-to-noise $(\mathrm{S} / \mathrm{N})$ ratio of 3. Method quantification limits (MQLs) were defined using a $\mathrm{S} / \mathrm{N}$ ratio of 10 . The IQLs and MQLs of all the target compounds are listed in Table S5. Field blanks were prepared for air and water and no contamination was detected. Procedure blanks were prepared for every eight samples and the results are listed in Table S5. For the compounds that were detected in the blank samples, the MQL was calculated as 3 times the standard deviation plus the mean value in the blanks. Concentrations were revised by subtracting the levels in the blank samples. Method validation results for water and sediment are presented in Table S6. Spike recoveries to surface water and sediment were generally within $60-110 \%$ with standard deviation below $25 \%$ for most compounds. The recovery of IS1 and IS2 are shown in Table S7. The mean recoveries were within $60 \% \pm 20 \%$ $\left({ }^{2} \mathrm{H}_{2-}{ }^{13} \mathrm{C}_{2}-10: 2 \mathrm{FTOH}\right)$ to $98 \% \pm 5 \%\left({ }^{13} \mathrm{C}_{4}-\mathrm{PFOA}\right)$. During the instrument injection, one blank and $10 \mu \mathrm{g} / \mathrm{L}$ standard samples were added in every 10 to 15 samples to monitor the contamination (all below the IQL) and instrument stability (standard deviations less than $\pm 10 \%)$.

\section{Results and discussion}

\subsection{PFASs in water, sediment, and air of the Bohai Sea}

The $\Sigma i$-PFAS concentrations in the dissolved phase in water ranged from 6.26 to $945 \mathrm{ng} / \mathrm{L}$ (mean $77 \pm 142 \mathrm{ng} / \mathrm{L}$ ) (Table 1). PFOA was the predominating compound accounting for 23-89\% (mean $68 \% \pm 13 \%$ ) of the $\Sigma i$-PFAS concentrations and higher concentrations were found in Laizhou Bay (Fig. S1), which was consistent with previous studies (Zhao et al., 2017). High PFOA concentrations could be attributed to usage in the fluoropolymer industries along the Laizhou Bay coast, for example as processing aids in TFE and PTFE products (Begley et al., 2005; Herzke et al., 2012; Wang et al., 2014a). The short-chained PFCA (C4 - C7) concentrations were from 1.80 to $96 \mathrm{ng} / \mathrm{L}$ (mean $13 \pm 15 \mathrm{ng} / \mathrm{L}$ ), lower than those of PFOA (3.2-845 ng/L, mean $60 \pm 127 \mathrm{ng} / \mathrm{L})$. High PFBA concentrations were detected in Laizhou Bay and the mouth of Liaodong Bay (Fig. S1). 2 PFSAs (C4, C6, C8, and C10) concentrations ranged from
$<$ MQL to $11.2 \mathrm{ng} / \mathrm{L}$ (mean $1.67 \pm 1.75 \mathrm{ng} / \mathrm{L}$ ). PFBS had a higher detection frequency (85\%) and concentrations (0.41-6.59 ng/L, mean $1.26 \pm 1.01 \mathrm{ng} / \mathrm{L})$ than those of PFOS (38\%, 0.30-2.91 ng/L, mean $0.74 \pm 0.61 \mathrm{ng} / \mathrm{L}$ ), indicating the application of shorterchained alternatives. In Liaodong and Bohai bays, PFBS concentrations were higher than those in other areas (Fig. S1), different from the PFOA distribution. 6:2 FTSA concentrations (0.03-20.7 ng/L, mean $0.74 \pm 0.61 \mathrm{ng} / \mathrm{L}$ ) were similar to those of PFBS, showing the use of novel PFASs in AFFF. The Cl-6:2 PFESA concentrations were around the MQL and HFPO-DA, PFECHS, and ADONA were not detected in more than $50 \%$ of the samples. In the suspended particle phase, the $\Sigma i$-PFAS concentrations ranged from 0.51 to $325 \mathrm{ng} / \mathrm{g}$ (mean $48 \pm 49 \mathrm{ng} / \mathrm{g}$ ) (Table 1). PFBA, PFOA and PFOS had high detection frequencies, i.e. 85,100 , and $92 \%$, respectively. The PFOA (0.32-302 ng/g dw, mean $30.5 \pm 43.7 \mathrm{ng} / \mathrm{g} \mathrm{dw}$ ) concentrations were much higher than those of PFBA $(0.02-4.41 \mathrm{ng} / \mathrm{g} \mathrm{dw}) . \mathrm{Cl}-6: 2$ PFESA was detected in $23 \%$ of the samples, with concentrations ranging from 0.06 to $3.95 \mathrm{ng} / \mathrm{g} \mathrm{dw}$, which were lower than those of PFOS $(0.44-21 \mathrm{ng} / \mathrm{g} \mathrm{dw})$. It was interesting that 3:3 FTCA could be detected in some river samples and the highest concentration was $35 \mathrm{ng} / \mathrm{L}$ at YAHR. 3:3 FTCA is a very short-chain fluorotelomer acid, presumably the degradation product of similar precursors such as those of other n:3 FTCA homologues (e.g., n:2 FTSAs can degrade to n:3 FTCAs); additionally, 3:3 FTCA could also degrade to ultrashort chain PFCAs (Chen et al., 2019; Kabore et al., 2018; Lang et al., 2017).

In the sediment, the $\Sigma i$-PFAS concentrations ranged from 0.70 to $4.13 \mathrm{ng} / \mathrm{g}$ dry wet $(\mathrm{dw})$ with an average value of $1.78 \pm 0.76 \mathrm{ng} / \mathrm{g} \mathrm{dw}$. Higher $\Sigma i$-PFAS concentrations were detected in Laizhou Bay and the depositional zone of the Liaodong Bay mouth (Fig. 2B). PFOA was the predominant compound ranging from 0.20 to $1.0 \mathrm{ng} / \mathrm{g} \mathrm{dw}$ $(0.46 \pm 0.22 \mathrm{ng} / \mathrm{g} \mathrm{dw})$. Compared to a previous study from the Bohai Sea (Gao et al., 2014), the PFOA concentration (0.06-2.70 ng/g dw) had decreased from 2011. The long-chained PFCAs (C9 - C11) have a higher detection frequency in sediment than that in the dissolved phase, indicating a stronger affinity to sediments than that of the short-chained compounds (Higgins and Luthy, 2006).

In the air, $\Sigma n$-PFAS concentrations contributed from 24 to $80 \%$ of the PPFASs, ranging from 199 to $678 \mathrm{pg} / \mathrm{m}^{3}\left(462 \pm 166 \mathrm{pg} / \mathrm{m}^{3}\right)$ (Table 1). 8:2 FTOH was the predominant compound and its concentrations ranged from 60.7 to $368 \mathrm{pg} / \mathrm{m}^{3}\left(191 \pm 111 \mathrm{pg} / \mathrm{m}^{3}\right)$. Compared to previous studies, 8:2 FTOH concentrations in 2017 were comparable to those in $2012\left(55-429 \mathrm{pg} / \mathrm{m}^{3}, 182 \pm 166 \mathrm{pg} /\right.$ $\mathrm{m}^{3}$ ) (Fang et al., 2018). Backward air trajectories showed that air masses with higher concentrations (A4, A5, and A6) originated from Shandong, Liaoning, and Jiangsu provinces and air masses with lower concentrations (A1, A2, and A3) from the eastern coastal provinces of China, Mongolia, and Russia (Fig. S3). In Shandong and Liaoning provinces, emissions from PFAS-related industrials were the major sources of PFASs in the environment (Meng et al., 2018; Yu et al., 2018b; Zhang et al., 2012; Zhao et al., 2013a).

Compared to previous studies, $\Sigma i$-PFAS concentrations (dissolved and particle phase, $19.3-970 \mathrm{ng} / \mathrm{L}$ ) in the surface water of the Bohai Sea were higher than those in the Yellow Sea (5.79-34.0 ng/L), East China Sea (0.13-3.32 ng/L), and South China Sea (0.13-1.02 ng/L)(Cai et al., 2012; Wang et al., 2019; Zhou et al., 2018). Joerss et al. (2019) reported that HFPO-DA and PFECHS were the predominant PFAS in water from the German Bight and the Baltic Sea, respectively, indicating a shift to alternative compounds in northern European countries. In China, C8 was still dominant in the Bohai Sea. In sediment, the $\Sigma i$-PFAS concentrations in the Bohai Sea were comparable to those in the Yellow Sea (below the limit of detection (<LOD) to $2.76 \mathrm{ng} / \mathrm{g} \mathrm{dw}$ ), German Bight, and Baltic Sea $(0.018-2.6 \mathrm{ng} / \mathrm{g} \mathrm{dw})$ but lower than those in the East China Sea (0.67-37 ng/g dw) (Gao et al., 2014; Joerss et al., 2019; Wang et al., 2018a). $\Sigma i$-PFAS concentrations in the air around the Bohai Sea were 
Table 1

Concentrations range of target PFASs in air, water, and sediment.

\begin{tabular}{|c|c|c|c|c|c|c|}
\hline \multirow[t]{2}{*}{ Compounds } & \multicolumn{2}{|c|}{ Dissolve phase (ng/L) } & \multicolumn{2}{|c|}{ Suspended particle phase (ng/g dw) } & \multirow[t]{2}{*}{ Sediment (ng/g dw) } & \multirow[t]{2}{*}{ Air $\left(\mathrm{pg} / \mathrm{cm}^{3}\right)$} \\
\hline & Sea & River & Sea & River & & \\
\hline PFBA & $<$ MQL-8.69 & $<$ MQL-531 & $<$ MQL-4.41 & <MQL-9.15 & $0.15-0.60$ & $17.0-73.2$ \\
\hline PFPeA & $<$ MQL-34.4 & $<$ MQL-479 & <MQL-6.01 & $<$ MQL-6.57 & $0.01-0.92$ & $1.00-28.2$ \\
\hline PFHxA & $0.89-33.4$ & $0.13-1985$ & $<M Q L-20.5$ & $<$ MQL-1.68 & $<$ MQL-0.88 & $23.1-103$ \\
\hline PFHpA & $<$ MQL-22 & $<$ MQL-2663 & $<$ MQL-33.4 & $<$ MQL-4.97 & $0.08-0.26$ & $5.40-28.9$ \\
\hline PFOA & $3.20-845$ & $0.96-7335$ & $0.32-302$ & $0.34-1140$ & $0.20-1.00$ & $17.0-92.6$ \\
\hline PFNA & $<$ MQL-1.73 & $<$ MQL-38.1 & $<$ MQL-3.74 & $<$ MQL-6.15 & $<$ MQL-0.47 & $3.87-32.5$ \\
\hline PFDA & $<$ MQL-0.59 & $<$ MQL-11.9 & $<$ MQL-19.2 & <MQL-18.6 & $<$ MQL-0.38 & $0.48-7.55$ \\
\hline PFUnDA & $<$ MQL-0.35 & $<\mathrm{MQL}-2.45$ & $<$ MQL-8.09 & $<$ MQL-5.85 & $<$ MQL-0.28 & $0.36-1.68$ \\
\hline PFDoDA & $<M Q L-0.06$ & $<$ MQL-0.067 & $<\mathrm{MQL}$ & $<$ MQL-0.75 & $<$ MQL-0.10 & $<$ MDL-2.09 \\
\hline PFBS & $<$ MQL-6.59 & $<\mathrm{MQL}-281$ & $<$ MQL-8.22 & $<$ MQL-4.19 & $<\mathrm{MQL}$ & $<$ MDL-4.75 \\
\hline PFHxS & $<\mathrm{MQL}-3.62$ & $<\mathrm{MQL}-305$ & $<\mathrm{MQL}-1.88$ & $<$ MQL-64.4 & $<$ MQL-0.15 & $0.70-4.86$ \\
\hline PFOS & $<$ MQL-2.91 & $<$ MQL-71.8 & $<$ MQL-2.90 & $<$ MQL-48.5 & $<$ MQL-0.20 & $1.76-6.54$ \\
\hline PFDS & $<$ MQL-0.15 & $<$ MQL-0.36 & $<M Q L-20.5$ & $<\mathrm{MQL}$ & $<\mathrm{MQL}$ & $<\mathrm{MQL}$ \\
\hline 4:2 FTSA & $<$ MQL-0.19 & $<$ MQL-0.77 & $<$ MQL-45.5 & $<$ MQL-0.77 & $<\mathrm{MQL}$ & $<\mathrm{MQL}$ \\
\hline $6: 2$ FTSA & $<$ MQL-20.7 & $<$ MQL-28.7 & $<$ MQL-11.2 & $<$ MQL-28.7 & $<$ MQL-0.20 & $<\mathrm{MQL}$ \\
\hline 8:2 FTSA & $<$ MQL-0.20 & $<$ MQL-0.16 & $<$ MQL-18.2 & $<$ MQL-0.52 & $<\mathrm{MQL}$ & $<\mathrm{MQL}$ \\
\hline 10:2 FTSA & $<M Q L-0.09$ & $<$ MQL-0.14 & $<$ MQL-13.2 & $<\mathrm{MQL}$ & $<\mathrm{MQL}$ & $<\mathrm{MQL}$ \\
\hline 3:3 FTCA & $<$ MQL-2.68 & $<$ MQL-35.2 & $<$ MQL-2.68 & $<$ MQL-35.2 & $<\mathrm{MQL}$ & $<\mathrm{MQL}$ \\
\hline 5:3 FTCA & $<$ MQL-0.03 & $<\mathrm{MQL}$ & $<\mathrm{MQL}$ & $<\mathrm{MQL}$ & $<\mathrm{MQL}$ & $<\mathrm{MQL}$ \\
\hline 7:3 FTCA & $<$ MQL-0.05 & $<$ MQL-0.27 & $<\mathrm{MQL}$ & $<M Q L-8.60$ & $<\mathrm{MQL}$ & $<\mathrm{MQL}$ \\
\hline $6: 2$ FTCA & $<M Q L-1.38$ & $<$ MQL-7.26 & $<\mathrm{MQL}$ & $<\mathrm{MQL}$ & $<\mathrm{MQL}$ & $3.82-14.3$ \\
\hline 8:2 FTCA & $<\mathrm{MQL}$ & $<\mathrm{MQL}$ & $<\mathrm{MQL}$ & $<\mathrm{MQL}$ & $<\mathrm{MQL}$ & $<\mathrm{MQL}$ \\
\hline 6:2 FTUCA & $<$ MQL-0.05 & $<$ MQL-1.47 & $<\mathrm{MQL}$ & $<\mathrm{MQL}$ & $<\mathrm{MQL}$ & $<$ MQL-0.88 \\
\hline 8:2 FTUCA & $<$ MQL-0.18 & $<$ MQL-0.34 & $<\mathrm{MQL}-1.44$ & $<$ MQL-1.20 & $<\mathrm{MQL}$ & $1.92-5.76$ \\
\hline Cl-6:2 PFESA & $<$ MQL-0.32 & $<$ MQL-36.9 & $<$ MQL-3.95 & <MQL-71.6 & $<$ MQL-0.04 & $<$ MQL-0.42 \\
\hline Cl-8:2 PFESA & $<$ MQL-0.04 & $<$ MQL-1.58 & $<$ MQL-0.42 & $<$ MQL-9.69 & $<\mathrm{MQL}$ & $<\mathrm{MQL}$ \\
\hline 6:2 diPAP & $<$ MQL-1.58 & $<$ MQL-0.057 & $<\mathrm{MQL}-16.1$ & $<\mathrm{MQL}-11.1$ & $<\mathrm{MQL}$ & $<\mathrm{MQL}-2.21$ \\
\hline 8:2 diPAP & $<$ MQL-0.15 & $<$ MQL-0.27 & $<M Q L-3.85$ & $<$ MQL-1.70 & $<\mathrm{MQL}$ & $<$ MQL-1.59 \\
\hline HFPO-DA & $<$ MQL-6.87 & $<$ MQL-663 & $<\mathrm{MQL}$ & $<$ MQL-96 & $<\mathrm{MQL}$ & $<\mathrm{MQL}$ \\
\hline ADONA & $<$ MQL-0.05 & $<\mathrm{MQL}-0.044$ & $<\mathrm{MQL}-1.60$ & $<$ MQL-0.29 & $<\mathrm{MQL}$ & $<\mathrm{MQL}$ \\
\hline PFECHS & $<$ MQL-0.11 & $<\mathrm{MQL}-0.53$ & $<\mathrm{MQL}-1.08$ & $<$ MQL-1.95 & $<\mathrm{MQL}$ & $<\mathrm{MQL}$ \\
\hline ¿i-PFASs & $6.26-945$ & $18.9-13300$ & $0.51-325$ & $0.64-1150$ & $0.70-4.13$ & $97.0-347$ \\
\hline $6: 2 \mathrm{FTOH}$ & - & - & - & - & - & $<\mathrm{MQL}-4.78$ \\
\hline 8:2 FTOH & - & - & - & - & - & $60.7-368$ \\
\hline 10:2 FTOH & - & - & - & - & - & $17.6-180$ \\
\hline N-MeFOSA & - & - & - & - & - & $<$ MQL-0.07 \\
\hline N-EtFOSA & - & - & - & - & - & $<$ MQL-0.09 \\
\hline N-EtFOSE & - & - & - & - & - & $<$ MQL-0.11 \\
\hline N-MeFOSE & - & - & - & - & - & $<\mathrm{MQL}$ \\
\hline$\Sigma$ n-PFASs & - & - & - & - & - & $80.8-542$ \\
\hline
\end{tabular}

-: no data.

higher than those in the Pearl River Delta $\left(53.7-225 \mathrm{pg} / \mathrm{m}^{3}\right)$ and in cities on the coasts of the Bohai and Yellow seas (23.6-94.5 pg/m $\mathrm{m}^{3}$ ) (Liu et al., 2019; Yu et al., 2018b).

\subsection{PFASs in river water}

In the water samples from 35 rivers around the Bohai Sea, $28 i$ PFASs, except 5:3 and 8:2 FTCA, were detected (Tables S12 and S13). The $\Sigma i$-PFAS concentrations ranged from 10.2 to $13,300 \mathrm{ng} / \mathrm{L}$ with an average concentration of $849 \pm 2380 \mathrm{ng} / \mathrm{L}$ in the dissolved phase and $0.14-1150 \mathrm{ng} / \mathrm{g} \mathrm{dw}$ with an average of $66.4 \pm 199 \mathrm{ng} / \mathrm{g} \mathrm{dw}$ in the suspended particle phase (Table 1 ). As with seawater, PFOA was the dominant compound in both phases in the river water, with concentrations ranging from 0.96 to $7340 \mathrm{ng} / \mathrm{L}$ and $0.13-1140 \mathrm{ng} / \mathrm{g}$ $\mathrm{dw}$, respectively. The compositions of other $i$-PFASs differed in the two phases. PFHxA (1.02-1990 ng/L), PFHpA ( $<$ MQL to 2660 ng/L), and PFBA ( $<\mathrm{MQL}$ to $531 \mathrm{ng} / \mathrm{L}$ ) were the major compounds in the dissolved phase whereas PFHxS (<MDL to $64.4 \mathrm{ng} / \mathrm{g} \mathrm{dw}$ ), PFOS ( $<$ MDL to $61.5 \mathrm{ng} / \mathrm{g} \mathrm{dw}$ ), and Cl-6:2 PFESA ( $<$ MDL to $71.6 \mathrm{ng} / \mathrm{g} \mathrm{dw}$ ) were present in higher concentrations than the other compounds in the suspended particle phase.

The highest concentration (dissolved and particle phase) was observed in the Xiaoqing River (XQR, $13500 \mathrm{ng} / \mathrm{L}$ ) at Hotspot 21 in Shandong Province, which was three orders of magnitude higher than the median level in the other rivers (95.2 ng/L, Fig. 2D and Table S15). The other two rivers in Hotspot 1, the Zhimai River (ZMR, $3510 \mathrm{ng} / \mathrm{L}$ ) and the Tahe River (TAHR, $2270 \mathrm{ng} / \mathrm{L}$ ), had lower PFAS concentrations than the Xiaoqing River; thus, the Zhimai and Tahe rivers as well as Xiaoqing River could be the major sources of the PFASs in Laizhou Bay (Chen et al., 2017a; Heydebreck et al., 2015; Zhou et al., 2018). PFHpA, PFHxA, and PFBS contributed $10-20 \%$ of the $\Sigma i$-PFAS concentrations in the river waters, indicating the use of shorter-chained compounds. At Hotspot 2, also in Shandong Province, the $\Sigma i$-PFAS concentrations were $3750 \mathrm{ng} / \mathrm{L}$ in the Dehuixin River (DHXR), $2510 \mathrm{ng} / \mathrm{L}$ in the Majia River (MJR), and $1240 \mathrm{ng} / \mathrm{L}$ in the Zhangweixin River (ZWXR). All PFOA contributions were greater than $98 \%$ in the three rivers, in contrast to Hotspot 1 . These two hotspots were both located at fluorotelomer industrial parks, which might be the source of the PFASs in the Bohai Sea (Chen et al., 2017a; Song et al., 2018). In all other rivers, shortchained PFASs were detected with greater frequency and at higher concentrations than the long-chained compounds. In the Ziyaxin River (ZYXR), PFHxS (308 ng/L) and PFBS (281 ng/L) concentrations were higher than that of PFOA $(15.2 \mathrm{ng} / \mathrm{L})$. The Ziyaxin River is an artificial river and runs into Bohai Bay through Tianjin City, carrying domestic and industrial waste (Chen et al., 2017a; Zhou et al., 2018). In the Xiaoling River (XLR), PFBA and PFBS were the predominant PFASs at concentrations of 199 and $170 \mathrm{ng} / \mathrm{L}$, 

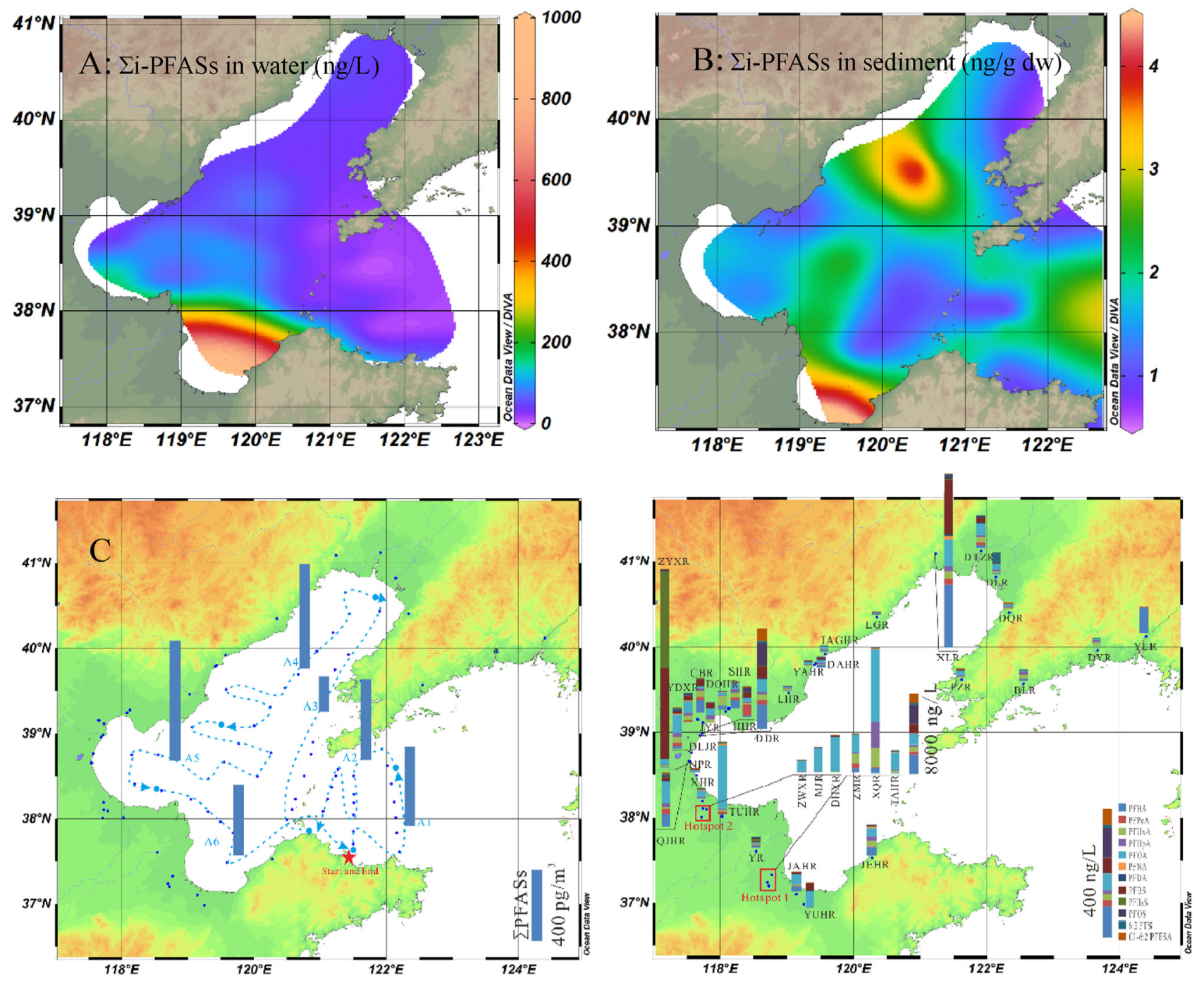

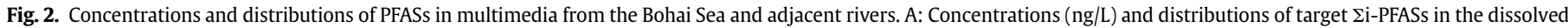

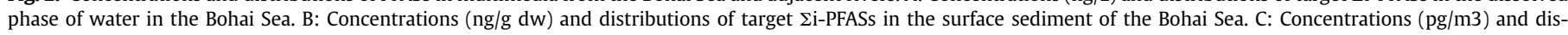

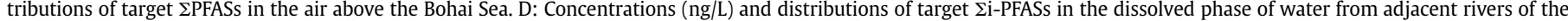
Bohai Sea.

respectively, which were higher than those of PFOA (86.2 ng/L). The Xiaoling River is one of the rivers in Liaoning Province that is part of the Liaohe River system, whose watershed has been polluted by PFASs (Wang et al., 2012).

In addition to short-chained PFASs, some other emerging alternatives showed high concentrations and/or detection frequencies in river water. HFPO-DA concentrations in most samples were lower than the MQL. However, notably, in Xiaoqing, Dagu Drainage and Chaobai River, the HFPO-DA concentrations (160-663 ng/L) were at high levels. HFPO-DA is known as an APFO or PFOA alternative that has been produced as a processing aid for fluoropolymer resin manufacturing since 2010 (Heydebreck et al., 2015). It is chemically stable and persistent when released into the environment (ECHA, 2019). The HFPO-DA concentration in seawater was lower than that in the rivers, possibly because of the dilution and dispersion processes with coastal water. 6:2 FTSA and Cl-6:2 PFESA were widely detected in the dissolved phase; the detection frequency of these were $100 \%$ and $70 \%$, respectively. This suggests their widespread production, use, and emission around the Bohai Sea. These two emerging compounds have been applied in AFFF and metal plating, respectively (Wei et al., 2018; Xie et al.,
2013). The highest 6:2 FTSA (28.7 ng/L) concentration was detected in the Daliao River (DLR), suggesting the use of AFFF in Liaoning Province. The highest $\mathrm{Cl}-6: 2$ PFESA (42.8 ng/L) concentration was detected in the Dagu Drainage River (DDR), which also had relatively high PFOS (75.8 ng/L) and 6:2 FTSA (8.20 ng/L) concentrations, indicating the source of metal plating in Tianjin City. The correlation analysis showed that PFOS concentrations were significantly correlated with 6:2 FTSA $(\mathrm{p}<0.01$ ) and Cl-6:2 PFESA $(p<0.01)$ in the river samples, indicating a similar source of legacy and alternative compounds. Additionally, the 6:2 FTSA contributions to $\Sigma i$-PFASs in the Bohai Sea $(2.3 \% \pm 8 \%)$ were greater than those in the rivers $(1.8 \% \pm 4 \%)$, suggesting the release from industry or AFFF related products (Mejia-Avendano et al., 2017; Wang et al., 2013c).

\subsection{Distribution coefficient of $i$-PFASs}

The field-based $\log K_{\mathrm{d}}$ and $\log K_{\mathrm{oc}}$ values for $i$-PFASs were calculated referring to previous studies with modification, and the details were presented in SI materials (Chen et al., 2015; Li et al., 2020). The suspended particle-derived and sediment-derived log 
Table 2

$\log K_{\mathrm{d}}$ and $\log K_{\mathrm{oc}}$ values for $i$-PFASs.

\begin{tabular}{|c|c|c|c|c|}
\hline \multirow[t]{2}{*}{ i-PFASs } & \multicolumn{2}{|c|}{ Particle-dissolved phase } & \multicolumn{2}{|c|}{ Sediment- dissolved phase } \\
\hline & Sea $\log K_{\mathrm{d}}$ & River $\log K_{\mathrm{d}}$ & $\log K_{\mathrm{d}}$ & $\log K_{\mathrm{oc}}$ \\
\hline PFBA & $2.58 \pm 0.66$ & $1.84 \pm 0.71$ & $2.23 \pm 0.62$ & $4.21 \pm 0.63$ \\
\hline PFPeA & $3.31 \pm 0.18$ & 2.61 & $1.89 \pm 0.42$ & $3.88 \pm 0.40$ \\
\hline PFHxA & $3.58 \pm 0.34$ & $2.17 \pm 0.52$ & $2.02 \pm 0.38$ & $3.96 \pm 0.38$ \\
\hline PFHpA & $3.71 \pm 0.35$ & $1.86 \pm 1.40$ & $1.78 \pm 0.38$ & $3.76 \pm 0.37$ \\
\hline PFOA & $2.78 \pm 0.57$ & $2.18 \pm 0.96$ & $1.15 \pm 0.40$ & $3.11 \pm 0.42$ \\
\hline PFNA & $3.59 \pm 0.20$ & $2.95 \pm 1.13$ & $2.54 \pm 0.41$ & $4.50 \pm 0.37$ \\
\hline PFDA & $4.36 \pm 0.47$ & $3.59 \pm 0.48$ & $2.60 \pm 0.43$ & $4.59 \pm 0.42$ \\
\hline PFUnDA & $4.27 \pm 0.24$ & $3.89 \pm 0.59$ & $2.97 \pm 0.39$ & $5.04 \pm 0.36$ \\
\hline PFBS & $3.28 \pm 0.47$ & $2.58 \pm 1.31$ & - & - \\
\hline PFHxS & $3.43 \pm 0.78$ & $3.08 \pm 0.77$ & $2.38 \pm 0.33$ & $4.31 \pm 0.30$ \\
\hline PFOS & $3.69 \pm 0.43$ & $2.9 \pm 0.88$ & $2.39 \pm 0.49$ & $4.38 \pm 0.45$ \\
\hline 6:2 FTSA & $4.32 \pm 0.33$ & $2.65 \pm 0.24$ & $1.94 \pm 0.72$ & $3.89 \pm 0.73$ \\
\hline $8: 2$ FTSA & 4.97 & - & - & - \\
\hline 6:2 FTUCA & - & - & $3.79 \pm 0.22$ & $5.71 \pm 0.26$ \\
\hline $8: 2$ FTUCA & 4.02 & 3.91 & - & - \\
\hline 6:2 diPAP & 4.02 & $4.58 \pm 0.66$ & - & - \\
\hline 8:2 diPAP & $4.71 \pm 0.48$ & $3.76 \pm 0.85$ & - & - \\
\hline Cl-6:2 PFESA & $4.11 \pm 0.58$ & $3.17 \pm 0.76$ & - & - \\
\hline Cl-8:2 PFESA & - & 5.43 & - & - \\
\hline ADONA & $4.68 \pm 0.15$ & 3.82 & - & - \\
\hline
\end{tabular}

$K_{\mathrm{d}}$ values ranged from $2.58 \pm 0.66$ (PFBA) to 4.97 (8:2 FTSA) and $1.84 \pm 0.71$ (PFBA) to 5.43 ( $\mathrm{Cl}-8: 2$ PFESA), respectively (Table 2$)$. Except for 6:2 diPAP, the particle-derived $\log K_{\mathrm{d}}$ values for seawater and particles were higher than those for rivers, which might related to the higher salinities in seawater than river water (Higgins and Luthy, 2006). Negative correlations between the PFBA, PFOA, PFDA, PFUnDA, and PFOS concentrations and suspended particle contents were found, which might be related to the specific surface area and organic matter (Munoz et al., 2017). Except for PFHxS, the PFSAs had higher $\log K_{d}$ values than those of the PFCAs in sea and river water due to the sulfonic tail (Higgins and Luthy, 2006).

The $\log K_{\mathrm{d}}$ values for $i$-PFASs between the sediment and dissolved phase ranged from $1.15 \pm 0.40$ (PFOA) to $3.79 \pm 0.22(6: 2$ FTUCA); these were lower than particle-derived $\log K_{\mathrm{d}}$ values probably due to the higher sorption capacity of suspended particles than sediment (Table 2) (Li et al., 2020; Shan et al., 2014). The organic matter normalized $\log K_{\mathrm{oc}}$ values for $\Sigma i$-PFASs in the sediment ranged from $3.11 \pm 0.42$ (PFOA) to $5.71 \pm 0.26$ (6:2 FTUCA). The $\log K_{\mathrm{d}}$ and $\log K_{\mathrm{oc}}$ of PFOA were lowest in the sediment at $1.15 \pm 0.40$ and $3.11 \pm 0.42$, respectively; however, these were higher than those in the South Bohai coastal watersheds $\left(\log K_{\mathrm{d}}\right.$ : $0.63 \pm 0.51, \log K_{\text {oc }}: 2.68 \pm 0.51$ ) (Zhu et al., 2014) and in the Netherlands ( $\left.\log K_{\mathrm{oc}}: 2.63\right)$ (Kwadijk et al., 2010). The $\log K_{\mathrm{d}}$ and $\log$ $K_{\mathrm{oc}}$ values for PFOS between the sediment and water were $2.39 \pm 0.49$ and $4.38 \pm 0.45$, respectively; these were at the same level as the $\log K_{\mathrm{d}}$ value in Ethiopia $(2.3 \pm 0.47)$ (Ahrens et al., 2016) but higher than those in the South Bohai coastal watersheds (log $K_{\mathrm{d}}: 1.7 \pm 0.39$ ) (Zhu et al., 2014). The normalized distribution coefficients of TOC $\left(f_{\text {oc }}\right)$ between the sediment and water were calculated (see the SI), and significant correlations were found between the $f_{\text {oc }}$ and $K_{\mathrm{d}}$ of PFPeA $(\mathrm{P}<0.01)$, PFHpA $(\mathrm{P}<0.05)$, and PFNA $(P<0.05)$. There were also significant correlations between the salinity and the $K_{\mathrm{d}}$ of $6: 2$ FTSA $(\mathrm{P}<0.01)$ and between the electrical conductivity and $K_{\mathrm{d}}$ of 6:2 FTSA $(\mathrm{P}<0.01)$. Beyond these, there were no significant correlations. These results are similar to those of previous reports, for instance, a study of the Bohai coast suggested that $f_{\text {oc }}$ was not significantly correlated with the $K_{\mathrm{d}}$ of PFASs ( $p>0.05$ ) except PFNA, PFDA, and PFHxS (Zhu et al., 2014), while a study of the Youngsan and Nakdong river estuarine systems showed that the $\mathrm{pH}$ and $f_{\text {oc }}$ were not significantly related to the $K_{\mathrm{d}}$ for the $i$-PFASs (Hong et al., 2013).

\subsection{Riverine $i$-PFAS discharge fluxes}

The $\Sigma i$-PFAS discharges from 34 rivers (runoff flowrate available) to the Bohai Sea were estimated using the method shown in the SI; the results are shown in Fig. 3 and Tables S13 and S14. Runoff data are referenced from previous reports (2016; Cui, 2008; Wang et al., 2016a). The riverine discharges of $\Sigma i$-PFASs were $20.3 \mathrm{t} / \mathrm{y}$ via the dissolved phase and $0.30 \mathrm{t} / \mathrm{y}$ via the particle phase. Approximately $90-99 \%$ of the $i$-PFASs input to the sea was through the dissolved phase. The fluxes in the dissolved phase were lower than those of 2015 ( $87 \mathrm{t} / \mathrm{y}$ ), partly because of the low concentrations and the lesser amount of rivers involved in the study (Chen et al., 2017b). The $\Sigma i$-PFAS fluxes in individual rivers ranged from $0.05 \mathrm{~kg} / \mathrm{y}$ (Daqing River, DQR) to 11,900 kg/y (Xiaoqing River, XQR) in the dissolved phase and from $0.004 \mathrm{~kg} / \mathrm{y}$ (Yuhe River, YHR) to $176 \mathrm{~kg} / \mathrm{y}$ (Xiaoqing River, XQR) in the particle phase. The Xiaoqing River contributed $58 \%$ of the $\Sigma i$-PFASs fluxes among all the rivers, which were higher than those of 2011 ( $4 \mathrm{t} / \mathrm{y}$ for $\Sigma \mathrm{i}$-PFASs and $3.6 \mathrm{t} / \mathrm{y}$ for PFOA) (Wang et al., 2014a), but lower than those of 2013 ( 43 t/y for $\Sigma \mathrm{i}$-PFASs and $\sim 41 \mathrm{t} / \mathrm{y}$ for PFOA) (Wang et al., 2016b), suggesting a decreasing trend during recent years. In the Yalu and Yellow rivers, the fluxes were $1810 \mathrm{~kg} / \mathrm{y}$ and $559 \mathrm{~kg} / \mathrm{y}$, respectively, which were
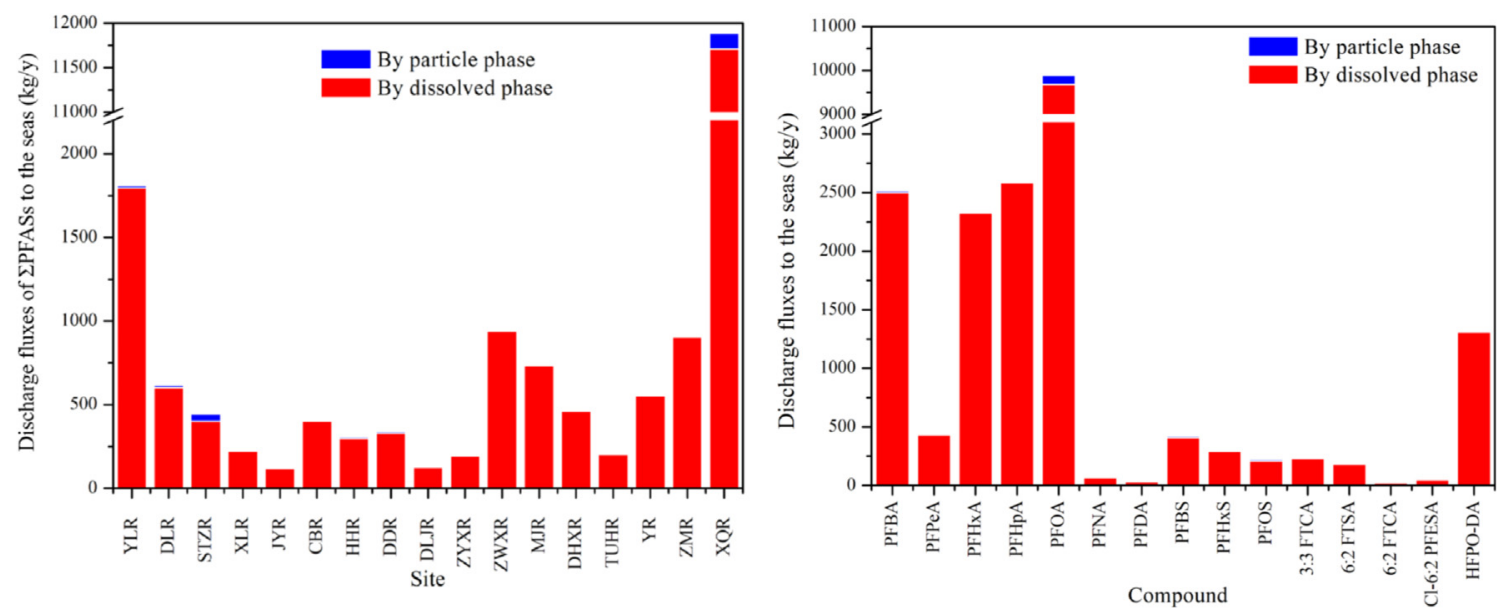

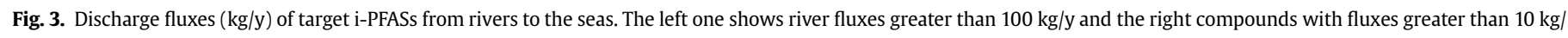
y. 
Table 3

Nontarget PFASs detected in seawater and river water.

\begin{tabular}{|c|c|c|c|c|c|c|c|c|c|c|}
\hline \multirow[t]{2}{*}{ Name } & \multirow[t]{2}{*}{ Acronym } & \multirow{2}{*}{$\begin{array}{l}\text { Ion Formula [M- } \\
1]\end{array}$} & \multirow{2}{*}{$\begin{array}{l}\text { Theoretical } \\
\mathrm{m} / \mathrm{z}\end{array}$} & \multicolumn{6}{|c|}{ Mass error (ppm) } & \multirow[t]{2}{*}{ Reference } \\
\hline & & & & DLR & HHR & YDXR & W25 & W30 & W38 & \\
\hline \multirow[t]{2}{*}{ Perfluoroalkyle sulfonate acid } & PFSAs & $\mathrm{C}_{2} \mathrm{O}_{3} \mathrm{SF}_{5}$ & 199 & - & 0.01 & - & - & - & - & Kaboré et al. (2018) \\
\hline & & $\mathrm{C}_{7} \mathrm{O}_{3} \mathrm{SF}_{15}^{-}$ & 449 & - & 1.40 & - & - & - & - & Kaboré et al. (2018) \\
\hline Hydrido-perfluorocaboxylic acid & H-PFCAs & $\mathrm{C}_{5} \mathrm{HO}_{2} \mathrm{~F}_{8}^{-}$ & 245 & - & 0.73 & - & 0.22 & 0.18 & & $\begin{array}{l}\text { Barzen-Hanson et al. } \\
\text { (2017) }\end{array}$ \\
\hline \multirow[t]{4}{*}{ Polyhydrido-perfluorocaboxylic acid } & $\mathrm{xH}-\mathrm{PFCAs}$ & $\mathrm{C}_{10} \mathrm{H}_{9} \mathrm{O}_{2} \mathrm{~F}_{10}^{-}$ & 351 & - & - & 2.80 & - & - & - & Gebbink et al. (2017) \\
\hline & & $\mathrm{C}_{12} \mathrm{H}_{11} \mathrm{O}_{2} \mathrm{~F}_{12}^{-}$ & 415 & - & 3.75 & - & - & 2.91 & 2.94 & Song et al. (2018) \\
\hline & & $\mathrm{C}_{14} \mathrm{H}_{13} \mathrm{O}_{2} \mathrm{~F}_{14}^{-}$ & 479 & - & - & - & - & - & 0.42 & Song et al. (2018) \\
\hline & & $\mathrm{C}_{20} \mathrm{H}_{17} \mathrm{O}_{2} \mathrm{~F}_{20}^{-}$ & 669 & - & 2.64 & - & - & - & - & Newton et al. (2017) \\
\hline Unsaturated perfluorocarboxylic acid & UPFCAs & $\mathrm{C}_{12} \mathrm{O}_{2} \mathrm{~F}_{21}^{-}$ & 575 & 3.03 & - & - & - & - & - & Wang et al. (2018b) \\
\hline \multirow[t]{3}{*}{ Hydrido-perfluoroalkane sulfonate acid } & H-PFSAs & $\mathrm{C}_{3} \mathrm{HO}_{3} \mathrm{SF}_{6}$ & 231 & - & - & - & - & - & 1.53 & $\begin{array}{l}\text { Barzen-Hanson et al. } \\
\text { (2017) }\end{array}$ \\
\hline & & $\mathrm{C}_{4} \mathrm{HO}_{3} \mathrm{SF}_{8}^{-}$ & 281 & - & - & - & - & 0.40 & - & $\begin{array}{l}\text { Barzen-Hanson et al. } \\
\text { (2017) }\end{array}$ \\
\hline & & $\mathrm{C}_{6} \mathrm{HO}_{3} \mathrm{SF}_{12}^{-}$ & 381 & 1.49 & - & - & - & - & - & Song et al. (2018) \\
\hline Polyhydrido-perfluorocaboxylic acid & $\mathrm{xH}-\mathrm{PFSAs}$ & $\mathrm{C}_{7} \mathrm{H}_{6} \mathrm{~F}_{10} \mathrm{SO}_{4}$ & 375 & - & 4.60 & - & - & - & - & Gebbink et al. (2017) \\
\hline \multirow[t]{2}{*}{ Unsaturated perfluoroalkane sulfonate acid } & UPFSA & $\mathrm{C}_{6} \mathrm{O}_{3} \mathrm{SF}_{11}^{-}$ & 361 & - & - & - & - & - & 0.46 & $\begin{array}{l}\text { Barzen-Hanson et al. } \\
\text { (2017) }\end{array}$ \\
\hline & & $\mathrm{C}_{8} \mathrm{O}_{3} \mathrm{SF}_{15}^{-}$ & 461 & - & 1.67 & - & - & - & - & $\begin{array}{l}\text { Barzen-Hanson et al. } \\
\text { (2017) }\end{array}$ \\
\hline \multirow[t]{2}{*}{ Chloro-perfluoroalkane sulfonate acid } & Cl-PFSA & $\mathrm{C}_{8} \mathrm{O}_{3} \mathrm{SClF}_{16}^{-}$ & 515 & - & - & - & 3.57 & 4.01 & - & $\begin{array}{l}\text { Barzen-Hanson et al. } \\
\text { (2017) }\end{array}$ \\
\hline & & $\mathrm{C}_{3} \mathrm{O}_{3} \mathrm{SClF}_{\overline{6}}^{-}$ & 265 & - & - & - & - & 3.73 & - & $\begin{array}{l}\text { Barzen-Hanson et al. } \\
\text { (2017) }\end{array}$ \\
\hline Ketone perfluoroalkyl sulphonate acid & K-PFSAs & $\mathrm{C}_{11} \mathrm{O}_{4} \mathrm{SF}_{21}^{-}$ & 627 & - & - & - & 2.67 & - & - & Baduel et al. (2017) \\
\hline n-Pentafluorosulfide-perfluoroalkane sulfonate acid & n-F5S-PFAS & $\mathrm{C}_{6} \mathrm{O}_{3} \mathrm{~S}_{2} \mathrm{~F}_{17}^{-1}$ & 507 & - & - & 0.01 & - & - & - & $\begin{array}{l}\text { Barzen-Hanson et al. } \\
\text { (2017) }\end{array}$ \\
\hline Oxa-unsaturated-perfluoroalkanoic acid & O-U-PFAA & $\mathrm{C}_{7} \mathrm{~F}_{11} \mathrm{O}^{-}$ & 341 & - & - & - & - & 0.40 & 0.00 & $\begin{array}{l}\text { Barzen-Hanson et al. } \\
\text { (2017) }\end{array}$ \\
\hline Unsaturated hydrido-perfluoroalkane ethers/alcohols & $\mathrm{H}-\mathrm{PFE} / \mathrm{AS}$ & $\mathrm{C}_{8} \mathrm{HOF}_{14}^{-}$ & 379 & - & - & - & 4.11 & 4.22 & - & Song et al. (2018) \\
\hline \multirow[t]{2}{*}{ Polyether perfluoroalkyl ether carboxylic acid } & polyether PFECAs & $\mathrm{C}_{4} \mathrm{O}_{4} \mathrm{~F}_{7}^{-}$ & 245 & 2.82 & - & - & - & - & 0.15 & Song et al. (2018) \\
\hline & & $\mathrm{C}_{6} \mathrm{O}_{6} \mathrm{~F}_{11}^{-}$ & 377 & - & 1.20 & - & - & - & - & Song et al. (2018) \\
\hline \multirow[t]{2}{*}{ Hexafluoropropylene oxide oligomers } & HFPO-oligomers & $\mathrm{C}_{6} \mathrm{O}_{3} \mathrm{~F}_{11}^{-}$ & 329 & - & - & - & 0.30 & - & - & Song et al. (2018) \\
\hline & & $\mathrm{C}_{9} \mathrm{O}_{4} \mathrm{~F}_{17}^{-}$ & 495 & - & - & - & - & - & 0.23 & Song et al. (2018) \\
\hline N-Methylperfluoro-1-alkanesulfonamidoacetic acid & N-MeFASAA & $\mathrm{C}_{9} \mathrm{H}_{5} \mathrm{O}_{4} \mathrm{SNF}_{13^{-}}$ & 497 & - & - & - & 0.51 & - & - & $\begin{array}{l}\text { Barzen-Hanson et al. } \\
\text { (2017) }\end{array}$ \\
\hline $\begin{array}{l}\mathrm{N} \text {-carboxymethyldimethyl ammoniopropyl- } \\
\text { perfluoroalkane sulfonamide acid }\end{array}$ & N-CMAmPFASA & $\mathrm{C}_{11} \mathrm{H}_{14} \mathrm{O}_{4} \mathrm{SN}_{2} \mathrm{~F}_{9}^{-}$ & 441 & - & - & - & - & 4.61 & - & $\begin{array}{l}\text { Barzen-Hanson et al. } \\
\text { (2017) }\end{array}$ \\
\hline $\begin{array}{l}\text { N-dihydroxypropyldimethylammoniohydroxybutyl- } \\
\text { perfluoroalkanesulfonamide }\end{array}$ & $\begin{array}{l}\text { N-diHOPAmHOB- } \\
\text { FASA }\end{array}$ & $\mathrm{C}_{14} \mathrm{H}_{20} \mathrm{O}_{5} \mathrm{SN}_{2} \mathrm{~F}_{11}^{-}$ & 537 & 0.96 & - & - & - & - & - & $\begin{array}{l}\text { Barzen-Hanson et al. } \\
\text { (2017) }\end{array}$ \\
\hline $\begin{array}{l}\text { N-dihydroxypropyldimethylammoniohydroxybutyl- } \\
\text { perfluoroalkanesulfonamidopropylsulfonate acid }\end{array}$ & $\begin{array}{l}\text { N-diHOPAmHOB- } \\
\text { FASAPS }\end{array}$ & $\mathrm{C}_{14} \mathrm{H}_{26} \mathrm{O}_{8} \mathrm{~S}_{2} \mathrm{~N}_{2} \mathrm{~F}_{5}^{-}$ & 509 & - & 1.48 & - & - & - & - & $\begin{array}{l}\text { Barzen-Hanson et al. } \\
\text { (2017) }\end{array}$ \\
\hline $\begin{array}{l}\mathrm{N} \text {-dihydroxybutyl dimethyl ammoniopropyl } \\
\text { perfluoroalkane sulfon amide }\end{array}$ & N-diHOBAmP-FASA & $\mathrm{C}_{14} \mathrm{H}_{20} \mathrm{O}_{4} \mathrm{SN}_{2} \mathrm{~F}_{11}^{-}$ & 521 & 1.11 & - & - & 0.81 & - & - & $\begin{array}{l}\text { Barzen-Hanson et al. } \\
\text { (2017) }\end{array}$ \\
\hline
\end{tabular}

-: Not detected.

higher than those of $90 \%$ of the other rivers because of the large river runoff. The rivers in the hotspots had higher fluxes $(461-11900 \mathrm{~kg} / \mathrm{y})$ than those of the others $(0.06-1810 \mathrm{~kg} / \mathrm{y})$. For the individual compounds, PFOA had the highest total fluxes $(98,800 \mathrm{~kg} / \mathrm{y})$, followed by those of PFHxA (2590 kg/y) and PFBA $(2520 \mathrm{~kg} / \mathrm{y})$. The total HFPO-DA flux was $1310 \mathrm{~kg} / \mathrm{y}$, although it was detected in five rivers. The 6:2 FTSA and Cl-6:2 PFESA fluxes were $182 \mathrm{~kg} / \mathrm{y}$ and $54 \mathrm{~kg} / \mathrm{y}$, respectively, which were lower than that of PFOS $(224 \mathrm{~kg} / \mathrm{y})$, suggesting the contribution of alternatives was comparable to that of the legacy compounds.

In previous studies, air deposition, drain outlines, and riverine discharge were all investigated as the input pathways of PFASs to the Bohai Sea and the rivers, particularly rivers that run through hotspots, were the major source. For PFCAs, the large fluxes were all found in rivers emptying into Laizhou Bay. This could explain the high concentrations in the seawater from Laizhou Bay. For PFBS, large fluxes were found in the Ziyaxin River (ZYXR, $64.2 \mathrm{~kg} / \mathrm{y}$ ) and Xiaoling River (XLR, $68.1 \mathrm{~kg} / \mathrm{y}$ ), which discharge water to Liaodong Bay, and the Haihe River (HHR, $47.8 \mathrm{~kg} / \mathrm{y}$ ) and Ziyanxin River (ZYXR, $87.0 \mathrm{~kg} / \mathrm{y}$ ), which discharge water to Bohai Bay. Correspondingly, higher concentrations could be detected in seawater from these two bays. The distribution pattern of Cl-6:2 PFESA was similar to that of PFBS in the Bohai Sea and large fluxes could be found in rivers inputting water to Bohai and Liaodong bays. However, for some compounds, high riverine discharges did not accompany high concentrations in seawater. For instance, large fluxes of 6:2 FTSA were found in the Daliao River (DLR, $134 \mathrm{~kg} / \mathrm{y}$ ) and Liaodong Bay, but the seawater concentrations near the estuary were not higher than those of other areas, partly because of the lower emission volume as an alternative in AFFF.

\subsection{Emerging PFASs in seawater and estuary water}

Three seawater samples (W25, W30, and W38) and three river water samples (DLR, YDXR, and HHR) were selected at random to identify more emerging PFASs using high-magnetic field FT-ICRMS. In total, 29 nontarget compounds were found in 6 samples (Table 3) and 26 of them had linear perfluorocarbon chains shorter than or equivalent to $\mathrm{C} 8$. One long-chained ketone perfluoroalkyl sulfonate acid (K-PFSAs, $\mathrm{C}_{11} \mathrm{O}_{4} \mathrm{SF}_{21}$ ) which has a linear structure of $\mathrm{C}_{9} \mathrm{~F}_{21}^{-}$, was detected in W25. More suspected PFASs in the sea (16) were found than in the river (13). Three suspected compounds were found in both sea and river waters, i.e. polyhydridoperfluorocaboxylic acid $\left(\mathrm{C}_{12} \mathrm{H}_{11} \mathrm{O}_{2} \mathrm{~F}_{12}^{-}\right)$, polyether perfluoroalkyl 
ether carboxylic acid $\left(\mathrm{C}_{4} \mathrm{O}_{4} \mathrm{~F}_{7}^{-}\right)$, and $\mathrm{N}$-dihydroxybutyl dimethyl ammoniopropyl perfluoroalkane sulfon amide $\left(\mathrm{C}_{14} \mathrm{H}_{20} \mathrm{O}_{4} \mathrm{SN}_{2} \mathrm{~F}_{11}^{-}\right)$. In the river water, no compounds were detected in more than one sample, while in seawater, five compounds were suspected to have been detected in two of the three samples. Song et al. (2018) reported more PFCA-based compounds than PFSA-based compounds in Xiaoqing River water, which receives wastewater from fluorotelomer industrial parks (Song et al., 2018). In this study, an inverse phenomenon was found. For instance, five PFSA-based and two PFCA-based compounds were suspected in the Haihe River (HHR), which might be influenced by the use of AFFF (BarzenHanson et al., 2017). The target $\Sigma i$-PFAS concentrations in the Haihe River (98.1 ng/L) and Yongdingxin River (93.3 ng/L) were at the same levels. However, in the Yongdingxin River, only one suspected sulfonate acid $\left(\mathrm{C}_{6} \mathrm{O}_{3} \mathrm{~S}_{2} \mathrm{~F}_{17}^{-}\right)$was found. The Daliao River discharge water into Liaodong Bay, and sample DLR and W30 are geographically related. However, no compounds could be detected in both of these samples, implying complex transport processes in this area. W25 and W38 were at the mouth of Liaodong Bay. Different from W25, more PFCA-based compounds (five) were suspected than PFSA-based compounds (two) in W38.

For some specific structures, two short-chained PFSAs, perfluoropropane sulfonate acid (PFPrS, $\mathrm{C}_{2} \mathrm{O}_{3} \mathrm{SF}_{5}^{-}$) and perfluoroheptane sulfonate acid ( $\mathrm{PFHpS}, \mathrm{C}_{7} \mathrm{O}_{3} \mathrm{SF}_{15}^{-}$), were detected in the Haihe River, in which, PFOS and PFBS also have higher concentrations than those of most of the other natural rivers. PFPrS and PFHpS have been detected in tap water throughout the world (Kabore et al., 2018) and the occurrence in the Haihe River indicated discharge from domestic waste throughout the river basin. The trimer acid of HFPO (HFPO-TrA) was detected in W38. Song et al. (2018) reported this compound in fluorochemical industrial parks in the coastal area of the south Bohai Sea and in the northern Bohai Sea implying release from the nearby area. Barzen-Hanson et al. (2017) reported several compounds from electrochemical fluorination (ECF) processes and some of them were found in this study; for instance, N-dihydroxybutyl dimethyl ammoniopropyl perfluoroalkane sulfonamide (N-diHOBAmP-FASA, $\mathrm{C}_{14} \mathrm{H}_{20} \mathrm{O}_{4} \mathrm{SN}_{2} \mathrm{~F}_{11}^{-}$) was one ECF-derived compound which could have been detected both in river water and seawater.

Different from other high-resolution instruments, FT-ICR could not work tandem after a chromatography, which could separate the homologues via retention time. And the high cost could be a disadvantage for regular analysis of large sample series. In this paper, the nontarget studies revealed the occurrence of emerging PFASs in aquatic environment. With the intensities of target compounds, the approximate concentrations of the nontarget ones could be estimated at tens of picograms per liter.

\section{Conclusion}

This study investigated the concentrations and distributions of 39 PFASs in water, sediment, and air from the Bohai Sea and it surrounding rivers and estimated their fluxes from rivers to sea. PFOA was the predominant compound in the water and sediment. PFBA and PFBS were detected in the water at higher levels than those of the other compounds, and longer-chained $(C>8)$ homologues had a higher detection rate in the sediment. In the air, 8:2 FTOH was the predominant compound. The rivers run through the hotspots presented high concentrations and large discharge fluxes to the Bohai Sea. High concentrations of some alternatives, i.e. 6:2 FTSA, Cl-6:2 PFESA, HFPO-DA, and ADONA, have been found in certain rivers suggesting the routine monitoring needed in the future studies. HFPO-DA flux (1310 kg/y) from rivers to the Bohai Sea was higher than that of PFOS (224 kg/y), indicating the intensive release from the hotspots. The distribution coefficients between the particle and dissolved phases in the sea were higher than those in the rivers, while the mechanism needs more investigation. Using high-resolution mass spectrometry, an additional 29 nontarget compounds were found in the river water and seawater.

\section{Declaration of competing interest}

The authors declare that they have no known competing financial interests or personal relationships that could have appeared to influence the work reported in this paper.

\section{CRediT authorship contribution statement}

Zhen Zhao: Conceptualization, Methodology, Software, Writing - review \& editing, Data curation. Xianghui Cheng: Data curation, Writing - original draft, Investigation. Xia Hua: Visualization, Investigation, Data curation. Bin Jiang: Software, Resources. Chongguo Tian: Investigation, Resources. Jianhui Tang: Conceptualization, Investigation, Writing - review \& editing, Supervision. Qilu Li: Data curation, Writing - review \& editing, Supervision. Hongwen Sun: Resources, Project administration. Tian Lin: Resources, Funding acquisition. Yuhong Liao: Resources, Software. Gan Zhang: Resources, Funding acquisition.

\section{Acknowledgement}

This study was supported by the National Natural Science Foundation of China (NSFC 41977310, U1806207 and 41773138) and the Key Deployment Project of Centre for Ocean Mega-Research of Science, Chinese academy of sciences ( COMS2019J08). The authors would like to acknowledge the generous colleagues and postgraduate students who were working on Chuangxin 1 research vessel during the field sampling campaigns.

\section{Appendix A. Supplementary data}

Supplementary data to this article can be found online at https://doi.org/10.1016/j.envpol.2020.114391.

\section{References}

Ahrens, L., 2011. Polyfluoroalkyl compounds in the aquatic environment: a review of their occurrence and fate. J. Environ. Monit. 13, 20-31.

Ahrens, L., Gashaw, H., Sjöholm, M., Gebrehiwot, S.G., Getahun, A., Derbe, E., Bishop, K., Åkerblom, S., 2016. Poly- and perfluoroalkylated substances (PFASs) in water, sediment and fish muscle tissue from Lake Tana, Ethiopia and implications for human exposure. Chemosphere 165, 352-357.

Baduel, C., Mueller, J.F., Rotander, A., Corfield, J., Gomez-Ramos, M.-J., 2017. Discovery of novel per- and polyfluoroalkyl substances (PFASs) at a fire fighting training ground and preliminary investigation of their fate and mobility. Chemosphere 185, 1030-1038.

Barzen-Hanson, K.A., Roberts, S.C., Choyke, S., Oetjen, K., McAlees, A., Riddell, N., McCrindle, R., Ferguson, P.L., Higgins, C.P., Field, J.A., 2017. Discovery of 40 classes of per- and polyfluoroalkyl substances in historical aqueous filmforming foams (AFFFs) and AFFF-impacted groundwater. Environ. Sci. Technol. 51, 2047-2057.

Begley, T.H., White, K., Honigfort, P., Twaroski, M.L., Neches, R., Walker, R.A., 2005. Perfluorochemicals: potential sources of and migration from food packaging. Food Addit. Contam. 22, 1023-1031.

Buck, R.C., Franklin, J., Berger, U., Conder, J.M., Cousins, I.T., de Voogt, P., Jensen, A.A., Kannan, K., Mabury, S.A., van Leeuwen, S.P., 2011. Perfluoroalkyl and polyfluoroalkyl substances in the environment: terminology, classification, and origins. Integr. Environ. Asses. 7, 513-541.

Cai, M., Zhao, Z., Yang, H., Yin, Z., Hong, Q., Sturm, R., Ebinghaus, R., Ahrens, L., Cai, M., He, J., Xie, Z., 2012. Spatial distribution of per- and polyfluoroalkyl compounds in coastal waters from the East to South China Sea. Environ. Pollut. $161,162-169$.

Chen, X., Zhu, L., Pan, X., Fang, S., Zhang, Y., Yang, L., 2015. Isomeric specific partitioning behaviors of perfluoroalkyl substances in water dissolved phase, suspended particulate matters and sediments in Liao River Basin and Taihu Lake, China. Water Res. 80, 235-244.

Chen, H., Han, J., Zhang, C., Cheng, J., Sun, R., Wang, X., Han, G., Yang, W., He, X., 
2017a. Occurrence and seasonal variations of per- and polyfluoroalkyl substances (PFASs) including fluorinated alternatives in rivers, drain outlets and the receiving Bohai Sea of China. Environ. Pollut. 231, 1223-1231.

Chen, H., Wang, X., Zhang, C., Sun, R., Han, J., Han, G., Yang, W., He, X., 2017b. Occurrence and inputs of perfluoroalkyl substances (PFASs) from rivers and drain outlets to the Bohai Sea, China. Environ. Pollut. 221, 234-243.

Chen, M., Wang, Q., Zhu, Y.M., Zhu, L.Y., Xiao, B.W., Liu, M.L., Yang, L.P., 2019. Species dependent accumulation and transformation of $8: 2$ polyfluoroalkyl phosphate esters in sediment by three benthic organisms. Environ. Int. 133.

Cui, Z., 2008. 2008. Study on Scheme of Total Emission Control of Main Chemical Pollutants in 13 Cities Around Bohai Sea. Ocean University of China.

Dauchy, X., Boiteux, V., Colin, A., Bach, C., Rosin, C., Munoz, J.-F., 2019. Poly- and perfluoroalkyl substances in runoff water and wastewater sampled at a firefighter training area. Arch. Environ. Contam. Toxicol. 76, 206-215.

de Solla, S.R., De Silva, A.O., Letcher, R.J., 2012. Highly elevated levels of perfluorooctane sulfonate and other perfluorinated acids found in biota and surface water downstream of an international airport, Hamilton, Ontario, Canada. Environ. Int. 39, 19-26.

ECHA, 2019. MSC Unanimously Agrees that HFPO-DA Is a Substance of Very High Concern.

Fang, X.G., Wang, Q., Zhao, Z., Tang, J.H., Tian, C.G., Yao, Y.M., Yu, J.C., Sun, H.W., 2018. Distribution and dry deposition of alternative and legacy perfluoroalkyl and polyfluoroalkyl substances in the air above the Bohai and Yellow Seas, China. Atmos. Environ. 192, 128-135.

Florentin, A., Deblonde, T., Diguio, N., Hautemaniere, A., Hartemann, P., 2011. Impacts of two perfluorinated compounds (PFOS and PFOA) on human hepatoma cells: cytotoxicity but no genotoxicity? Int. J. Hyg Environ. Health 214, 493-499.

Gao, Y., Fu, J., Zeng, L., Li, A., Li, H., Zhu, N., Liu, R., Liu, A., Wang, Y., Jiang, G., 2014. Occurrence and fate of perfluoroalkyl substances in marine sediments from the Chinese Bohai Sea, Yellow sea, and East China sea. Environ. Pollut. 194, 60-68.

Gebbink, W.A., van Asseldonk, L., van Leeuwen, S.P.J., 2017. Presence of emerging per- and polyfluoroalkyl substances (PFASs) in river and drinking water near a fluorochemical production plant in The Netherlands. Environ. Sci. Technol. 51, 11057-11065.

Genualdi, S., Lee, S.C., Shoeib, M., Gawor, A., Ahrens, L., Harner, T., 2010. Global pilot study of legacy and emerging persistent organic pollutants using sorbentimpregnated polyurethane foam disk passive air samplers. Environ. Sci. Technol. 44, 5534-5539.

Herzke, D., Olsson, E., Posner, S., 2012. Perfluoroalkyl and polyfluoroalkyl substances (PFASs) in consumer products in Norway - a pilot study. Chemosphere 88, 980-987.

Heydebreck, F., Tang, J., Xie, Z., Ebinghaus, R., 2015. Alternative and legacy perfluoroalkyl substances: differences between European and Chinese river/estuary systems. Environ. Sci. Technol. 49, 8386-8395.

Higgins, C.P., Luthy, R.G., 2006. Sorption of perfluorinated surfactants on sediments, Environ. Sci. Technol. 40, 7251-7256.

Hong, S., Khim, J.S., Park, J., Kim, M., Kim, W.-K., Jung, J., Hyun, S., Kim, J.-G., Lee, H., Choi, H.J., Codling, G., Giesy, J.P., 2013. In situ fate and partitioning of waterborne perfluoroalkyl acids (PFAAs) in the Youngsan and Nakdong River Estuaries of South Korea. Sci. Total Environ. 445-446, 136-145.

Houtz, E.F., Sutton, R., Park, J.-S., Sedlak, M., 2016. Poly- and perfluoroalkyl substances in wastewater: significance of unknown precursors, manufacturing shifts, and likely AFFF impacts. Water Res. 95, 142-149.

Joerss, H., Apel, C., Ebinghaus, R., 2019. Emerging per- and polyfluoroalkyl substances (PFASs) in surface water and sediment of the North and Baltic Seas. Sci. Total Environ. 686, 360-369.

Kabore, H.A., Sung Vo, D., Munoz, G., Meite, L., Desrosiers, M., Liu, J., Sory, T.K., Sauve, S., 2018. Worldwide drinking water occurrence and levels of newlyidentified perfluoroalkyl and polyfluoroalkyl substances. Sci. Total Environ. 616, 1089-1100.

Kaboré, H.A., Vo Duy, S., Munoz, G., Méité, L., Desrosiers, M., Liu, J., Sory, T.K., Sauvé, S., 2018. Worldwide drinking water occurrence and levels of newlyidentified perfluoroalkyl and polyfluoroalkyl substances. Sci. Total Environ. 616-617, 1089-1100.

Karrman, A., Elgh-Dalgren, K., Lafossas, C., Moskeland, T., 2011. Environmental levels and distribution of structural isomers of perfluoroalkyl acids after aqueous firefighting foam (AFFF) contamination. Environ. Chem. 8, 372-380.

Kwadijk, C.J.A.F., Korytár, P., Koelmans, A.A., 2010. Distribution of perfluorinated compounds in aquatic systems in The Netherlands. Environ. Sci. Technol. 44, 3746-3751.

Lang, J.R., Allred, B.M., Field, J.A., Levis, J.W., Barlaz, M.A., 2017. National estimate of per- and polyfluoroalkyl substance (PFAS) release to US municipal landfill leachate. Environ. Sci. Technol. 51, 2197-2205.

LfU, 2016. In: Agency, B.E. (Ed.), PFOA Und ADONA Messungen an Der Probenahmestelle Alz

Li, F., Sun, H., Hao, Z., He, N., Zhao, L., Zhang, T., Sun, T., 2011. Perfluorinated compounds in Haihe River and Dagu drainage canal in Tianjin, China. Chemosphere 84, 265-271.

Li, Y., Feng, X., Zhou, J., Zhu, L., 2020. Occurrence and source apportionment of novel and legacy poly/perfluoroalkyl substances in Hai River basin in China using receptor models and isomeric fingerprints. Water Res. 168, 115145.

Lim, T.C., Wang, B., Huang, J., Deng, S., Yu, G., 2011. Emission inventory for PFOS in China: review of past methodologies and suggestions. Sci. World J. 11, 1963-1980.

Lin, Y., Ruan, T., Liu, A., Jiang, G., 2017. Identification of novel hydrogen-substituted polyfluoroalkyl ether sulfonates in environmental matrices near metal-plating facilities. Environ. Sci. Technol. 51, 11588-11596.

Liu, Z., Lu, Y., Wang, T., Wang, P., Li, Q., Johnson, A.C., Sarvajayakesavalu, S., Sweetman, A.J., 2016a. Risk assessment and source identification of perfluoroalkyl acids in surface and ground water: spatial distribution around a mega-fluorochemical industrial park, China. Environ. Int. 91, 69-77.

Liu, Z.Y., Lu, Y.L., Wang, T.Y., Wang, P., Li, Q.F., Johnson, A.C., Sarvajayakesavalu, S., Sweetman, A.J., 2016b. Risk assessment and source identification of perfluoroalkyl acids in surface and ground water: spatial distribution around a mega-fluorochemical industrial park, China. Environ. Int. 91, 69-77.

Liu, B., Xie, L., Zhang, H., Li, J., Wang, X., Dong, W., 2019. Spatial distribution of perfluorinated compounds in atmosphere of the Pearl River Delta, China. Arch. Environ. Contam. Toxicol.

MacInnis, J.J., Lehnherr, I., Muir, D.C.G., Quinlan, R., De Silva, A.O., 2019. Characterization of perfluoroalkyl substances in sediment cores from High and Low Arctic lakes in Canada. Sci. Total Environ. 666, 414-422.

McCord, J., Strynar, M., 2019. Identification of per- and polyfluoroalkyl substances in the cape fear river by high resolution mass spectrometry and nontargeted screening. Environ. Sci. Technol. 53, 4717-4727.

Mejia-Avendano, S., Munoz, G., Duy, S.V., Desrosiers, M., Benoit, P., Sauve, S., Liu, J. 2017. Novel fluoroalkylated surfactants in soils following firefighting foam deployment during the Lac-Megantic railway accident. Environ. Sci. Technol. 51, 8313-8323.

Meng, J., Wang, T., Wang, P., Zhang, Y., Li, Q., Lu, Y., Giesy, J.P., 2015. Are levels of perfluoroalkyl substances in soil related to urbanization in rapidly developing coastal areas in North China? Environ. Pollut. 199, 102-109.

Meng, J., Wang, T., Song, S., Wang, P., Li, Q., Zhou, Y., Lu, Y., 2018. Tracing perfluoroalkyl substances (PFASs) in soils along the urbanizing coastal area of Bohai and Yellow Seas, China. Environ. Pollut. 238, 404-412.

Munoz, G., Budzinski, H., Labadie, P., 2017. Influence of environmental factors on the fate of legacy and emerging per- and polyfluoroalkyl substances along the salinity/turbidity gradient of a macrotidal estuary. Environ. Sci. Technol. 51, 12347-12357.

Munoz, G., Liu, J., Vo Duy, S., Sauvé, S., 2019. Analysis of F-53B, Gen-X, ADONA, and emerging fluoroalkylether substances in environmental and biomonitoring samples: a review. Trends Environ. Anal. Chem. 23, e00066.

Newton, S., McMahen, R., Stoeckel, J.A., Chislock, M., Lindstrom, A., Strynar, M., 2017 Novel polyfluorinated compounds identified using high resolution mass spectrometry downstream of manufacturing facilities near Decatur, Alabama. Environ. Sci. Technol. 51, 1544-1552.

Pan, Y., Zhang, H., Cui, Q., Sheng, N., Yeung, L.W.Y., Sun, Y., Guo, Y., Dai, J., 2018 Worldwide distribution of novel perfluoroether carboxylic and sulfonic acids in surface water. Environ. Sci. Technol. 52, 7621-7629.

Prevedouros, K., Cousins, I.T., Buck, R.C., Korzeniowski, S.H., 2006. Sources, fate and transport of perfluorocarboxylates. Environ. Sci. Technol. 40, 32-44.

Regnery, J., Püttmann, W., 2010. Seasonal fluctuations of organophosphate concentrations in precipitation and storm water runoff. Chemosphere 78, 958-964.

Shan, G. Wei, M., Zhu, L., Liu, Z., Zhang, Y., 2014. Concentration profiles and spatial distribution of perfluoroalkyl substances in an industrial center with condensed fluorochemical facilities. Sci. Total Environ. 490, 351-359.

Song, X., Vestergren, R., Shi, Y., Huang, J., Cai, Y., 2018. Emissions, transport, and fate of emerging per- and polyfluoroalkyl substances from one of the major fluoropolymer manufacturing facilities in China. Environ. Sci. Technol. 52, 9694-9703.

UNEP, 2009. Governments Unite to Step-Up Reduction on Global DDT Reliance and Add Nine New Chemicals under International Treaty. Stockholm Convention.

UNEP, 2017. Request for Information on Pentadecafluorooctanoic Acid (CAS No. 335 67-1, PFOA, Perfluorooctanoic Acid), its Salts and PFOA-Related Compounds. Stockholm Convention.

USEPA, 2000. Phase-out Plan for POSFbased Products, U.S. EPA Administrative Record AR226-0588. U.S.Environmental Protection Agency, Washington, DC.

USEPA, 2006. 2010/2015 PFOA Stewardship Program. U.S. Environmental Protection Agency.

Wang, T., Wang, Y., Liao, C., Cai, Y., Jiang, G., 2009. Perspectives on the inclusion of perfluorooctane sulfonate into the stockholm convention on persistent organic pollutants. Environ. Sci. Technol. 43, 5171-5175.

Wang, T.Y., Khim, J.S., Chen, C.L., Naile, J.E., Lu, Y.L., Kannan, K., Park, J., Luo, W., Jiao, W.T., Hu, W.Y., Giesy, J.P., 2012. Perfluorinated compounds in surface waters from Northern China: comparison to level of industrialization. Environ. Int 42, 37-46.

Wang, P., Wang, T., Giesy, J.P., Lu, Y., 2013a. Perfluorinated compounds in soils from Liaodong Bay with concentrated fluorine industry parks in China. Chemosphere 91, 751-757.

Wang, S., Huang, J., Yang, Y., Hui, Y., Ge, Y., Larssen, T., Yu, G., Deng, S., Wang, B. Harman, C., 2013b. First report of a Chinese PFOS alternative overlooked for 30 Years: its toxicity, persistence, and presence in the environment. Environ. Sci. Technol. 47, 10163-10170.

Wang, Z., Cousins, I.T., Scheringer, M., Hungerbühler, K., 2013c. Fluorinated alternatives to long-chain perfluoroalkyl carboxylic acids (PFCAs), perfluoroalkane sulfonic acids (PFSAs) and their potential precursors. Environ. Int. 60, 242-248.

Wang, P., Lu, Y., Wang, T., Fu, Y., Zhu, Z., Liu, S., Xie, S., Xiao, Y., Giesy, J.P., 2014a. Occurrence and transport of 17 perfluoroalkyl acids in 12 coastal rivers in south Bohai coastal region of China with concentrated fluoropolymer facilities. Environ. Pollut. 190, 115-122.

Wang, Z., Cousins, I.T., Scheringer, M., Buck, R.C., Hungerbühler, K., 2014b. Global 
emission inventories for C4-C14 perfluoroalkyl carboxylic acid (PFCA) homologues from 1951 to 2030, Part I: production and emissions from quantifiable sources. Environ. Int. 70, 62-75.

Wang, Z., Cousins, I.T., Scheringer, M., Hungerbuehler, K., 2015a. Hazard assessment of fluorinated alternatives to long-chain perfluoroalkyl acids (PFAAs) and their precursors: status quo, ongoing challenges and possible solutions. Environ. Int. 75, 172-179.

Wang, Z., Xie, Z., Mi, W., Moeller, A., Wolschke, H., Ebinghaus, R., 2015b. Neutra poly/per-fluoroalkyl substances in air from the atlantic to the southern ocean and in antarctic snow. Environ. Sci. Technol. 49, 7770-7775.

Wang, D.-G., Zheng, Q.-D., Wang, X.-P., Du, J., Tian, C.-G., Wang, Z., Ge, L.-K., 2016a. Illicit drugs and their metabolites in 36 rivers that drain into the Bohai Sea and north Yellow Sea, north China. Environ. Sci. Pollut. Res. 23, 16495-16503.

Wang, P., Lu, Y., Wang, T., Meng, J., Li, Q., Zhu, Z., Sun, Y., Wang, R., Giesy, J.P., 2016b. Shifts in production of perfluoroalkyl acids affect emissions and concentrations in the environment of the Xiaoqing River Basin, China. J. Hazard Mater. 307, $55-63$.

Wang, Y., Vestergren, R., Shi, Y., Cao, D., Xu, L., Cai, Y., Zhao, X., Wu, F., 2016c Identification, tissue distribution, and bioaccumulation potential of cyclic perfluorinated sulfonic acids isomers in an airport impacted ecosystem. Environ. Sci. Technol. 50, 10923-10932.

Wang, Q.-W., Yang, G.-P., Zhang, Z.-m., Zhang, J., 2018a. Optimization of sample preparation and chromatography for the determination of perfluoroalkyl acids in sediments from the Yangtze Estuary and East China Sea. Chemosphere 205, $524-530$.

Wang, Y., Yu, N., Zhu, X., Guo, H., Jiang, J., Wang, X., Shi, W., Wu, J., Yu, H., Wei, S., 2018b. Suspect and nontarget screening of per- and polyfluoroalkyl substances in wastewater from a fluorochemical manufacturing park. Environ. Sci. Technol. 52, 11007-11016.

Wang, Q., Tsui, M.M.P., Ruan, Y., Lin, H., Zhao, Z., Ku, J.P.H., Sun, H., Lam, P.K.S., 2019. Occurrence and distribution of per- and polyfluoroalkyl substances (PFASs) in the seawater and sediment of the South China sea coastal region. Chemosphere 231, 468-477.

Wei, C., Wang, Q., Song, X., Chen, X., Fan, R., Ding, D., Liu, Y., 2018. Distribution, source identification and health risk assessment of PFASs and two PFOS alternatives in groundwater from non-industrial areas. Ecotoxicol. Environ. Saf. 152, $141-150$.

Weiner, B., Yeung, L.W.Y., Marchington, E.B., D’Agostino, L.A., Mabury, S.A., 2013. Organic fluorine content in aqueous film forming foams (AFFFs) and biodeg radation of the foam component $6: 2$ fluorotelomermercaptoalkylamido sulfonate ( $6: 2$ FTSAS). Environ. Chem. 10, 486-493.
Xiao, F., Golovko, S.A., Golovko, M.Y., 2017. Identification of novel non-ionic, cationic, zwitterionic, and anionic polyfluoroalkyl substances using UPLC-TOF-MSE high-resolution parent ion search. Anal. Chim. Acta 988, $41-49$.

Xie, S., Wang, T., Liu, S., Jones, K.C., Sweetman, A.J., Lu, Y., 2013. Industrial source identification and emission estimation of perfluorooctane sulfonate in China. Environ. Int. 52, 1-8.

Xu, L., Shi, Y., Li, C., Song, X., Qin, Z., Cao, D., Cai, Y., 2017. Discovery of a novel polyfluoroalkyl benzenesulfonic acid around oilfields in northern China. Environ. Sci. Technol. 51, 14173-14181.

Yu, N., Guo, H., Yang, J., Jin, L., Wang, X., Shi, W., Zhang, X., Yu, H., Wei, S., 2018a. Non-target and suspect screening of per- and polyfluoroalkyl substances in airborne particulate matter in China. Environ. Sci. Technol. 52, 8205-8214.

Yu, S.Y., Liu, W.J., Xu, Y.S., Zhao, Y.Z., Wang, P., Wang, X., Li, X.Y., Cai, C.Y., Liu, Y., Xiong, G.N., Tao, S., Liu, W.X., 2018b. Characteristics of perfluoroalkyl acids in atmospheric PM10 from the coastal cities of the Bohai and Yellow Seas, Northern China. Environ. Pollut. 243, 1894-1903.

Zhang, L., Liu, J., Hu, J., Liu, C., Guo, W., Wang, Q., Wang, H., 2012. The inventory of sources, environmental releases and risk assessment for perfluorooctane sulfonate in China. Environ. Pollut. 165, 193-198.

Zhao, L., Zhou, M., Zhang, T., Sun, H., 2013a. Polyfluorinated and perfluorinated chemicals in precipitation and runoff from cities across eastern and Central China. Arch. Environ. Contam. Toxicol. 64, 198-207.

Zhao, Z., Tang, J., Xie, Z., Chen, Y., Pan, X., Zhong, G., Sturm, R., Zhang, G., Ebinghaus, R., 2013b. Perfluoroalkyl acids (PFAAs) in riverine and coastal sediments of Laizhou Bay, North China. Sci. Total Environ. 447, 415-423.

Zhao, Z., Tang, J., Mi, L., Tian, C., Zhong, G., Zhang, G., Wang, S., Li, Q., Ebinghaus, R. Xie, Z., Sun, H., 2017. Perfluoroalkyl and polyfluoroalkyl substances in the lower atmosphere and surface waters of the Chinese Bohai Sea, Yellow Sea, and Yangtze River estuary. Sci. Total Environ. 599, 114-123.

Zhou, Z., Liang, Y., Shi, Y., Xu, L. Cai, Y., 2013. Occurrence and transport of perfluoroalkyl acids (PFAAs), including short-chain PFAAs in Tangxun lake, China. Environ. Sci. Technol. 47, 9249-9257.

Zhou, Y, Wang T, Li, O, Wang, P. Li, L, Chen, S, Zhang, Y, Khan, K., Meng J, 2018. Spatial and vertical variations of perfluoroalkyl acids (PFAAs) in the Bohai and Yellow Seas: bridging the gap between riverine sources and marine sinks. Environ. Pollut. 238, 111-120.

Zhu, Z., Wang, T., Wang, P., Lu, Y., Giesy, J.P., 2014. Perfluoroalkyl and polyfluoroalkyl substances in sediments from South Bohai coastal watersheds, China. Mar. Pollut. Bull. 85, 619-627. 